\title{
Labor Immobility in Japan: Its causes and consequences*
}

\author{
Kenn Ariga and Ryosuke Okazawa \\ Institute of Economic Research, and Graduate School of Economics \\ (resp.), Kyoto University, Kyoto Japan
}

\begin{abstract}
This paper builds and calibrates a model of competitive search that can reproduce a set of stylized facts concerning major impacts of the decade long stagnation and subsequent changes in the labor market in Japan. We highlight the role played by varying degrees of relation specific investments in forming employment relations. By embedding such a system of employment in an economy plagued with limited capital mobility, we show that the macro technology shocks can generate upward drift in Beveridge curve, pro-longed periods of labor adjustments, decline in the share of jobs with costly investment in training, and strong cohort effects. The paper also simulates impacts of 'zombie' jobs, firing cost, and subsidy for training. Through these simulations we show that the combination of the macro technology shocks and high cost of re-training is responsible for the sluggish labor adjustment, shrinking core employment, and stagnant productivity.

Journal of Economic Literature Classification: E24, J24, J64
\end{abstract}

\section{Introduction}

As the Japanese economy quickly recovered from two oil shocks, the 1980's was the decade of the continued high growth and global proliferation of the Japanese consumer electronics and cars. As a result, some of the unique features of the Japanese economy, especially the employment system, attracted much academic attentions. Long term employment, intensive training, and strong worker attachments are considered as the key to the competitive edge and high productivity growth of the economy, especially the manufacturing sector.

In 1991, just before the onset of the decade long stagnation of the economy, $82 \%$ of the 44 million employees in Japan had regular ${ }^{1}$ and full time jobs. The rest of employees, either temporary or part time or both, comprised the remaining $18 \%$, or 7 and a half million, out of which roughly $80 \%$ of them (5.5 million) were female. As

\footnotetext{
*Earlier version of this paper was presented in seminars at Kyusyu and Tohoku Universities, Search Theory workshop at Kansai University, Search Theory Workshop Conference in Osaka, and book conferences in New York and San Francisco. We wish to thank Julen Esteban-Pretel, Kyoji Fukao, Takeo Hosi, Ryoichi Imai, Ricardo Lagos, Gary Ramey, Robert Shimer, Daishin Yasui, as well as three editors of the book, Koichi Hamada, Anil Kashyap and David Weinstein. All the remaining errors are our own.

1'Regular' (Joyo) workers refers to those under the employment contracts without pre-specified length of the employment. In what follows, we use the regular and full time workers as our benchmark for the core employment in Japan.
} 
of late 2007, around 34 million had regular and full time jobs, which now account only for $2 / 3$ of the total employees ${ }^{2}$ The share of male in the non-core employment rose steadily, comprising now roughly one third, or more than 5 million. The size of regular and full time employees peaked in 1994 at 38 millions. Since then, Japan lost 3.3 million such jobs while temporary and/or part time jobs increased by 7.5 millions. This is shown in Figure 1. The impact of the decline of the core employment was the hardest among the younger cohorts: in 1998, among the age 15-24 cohort, $83 \%$ of them had regular, full time jobs. By 2006, this share dropped to $54 \% .^{3}$

\section{Figure 1 around here}

The other side of the decline in the core employment is the rapid increase in temporary and part time jobs. As the turnover rates of these non-core jobs are much higher, the economy witnessed long swing and sizable outward shift of the Beveridge curve. See Figure 2. As of 2007, the registered vacancy rate stands at .037, somewhat higher than .034, the figure for 1990, the peak year before the long stagnation. Yet the unemployment rate is more than doubled compared to $2.1 \%$ in 1990 .

\section{Figure 2 around here}

The sharp increase in unemployment in the last few years of the millennium until 2002 mirrors the depressed labor market and historically low rate of accessions. Even at the peak, the separation rate was only comparable to the level during the bubble years. In retrospect, the sharp increase in unemployment was an outcome not only of the increase in separations, but also of the historical low rate of accessions. See Figures 3 and 4 . The declining mobility is masked, however, by the steady increase in the share of part time and temporary jobs wherein the average duration of single spell of jobs is much shorter. In short, it is the apparent sluggishness and declining share of the core employment that shapes the landscape of the labor market in Japan.

\section{Figures 3 and 4 around here}

The shrinking size of the core employment also mirrors the secular decline of the sectors characterized by higher productivity, stable employment and intensive training. For example, between 1990 and 2006, the share of manufacturing sector declined from $29.5 \%$ to $25.7 \%$ in GDP share, and $26.3 \%$ to $18.7 \%$ in employment ${ }^{4}$. The other side of this decline is the secular increase in the share of relatively low productivity service sectors. For example, as of 2006, retail and wholesale sector has roughly the same share $(18.0 \%)$ in employment as the manufacturing, whereas its GDP share is only $12.5 \%$ in 2006 .

The erosion of the core of the high productivity sector is seen also in terms of TFP growth. Numerous studies demonstrate that the substantial decline in the TFP growth occurred in manufacturing sector. Moreover, many studies find that a significant portion of the deceleration of the aggregate TFP growth is attributable

\footnotetext{
211 millions of these temporary or part time workers - more than $60 \%$ of these, $25 \%$ of all the employees in Japan - earn 2 million yen (roughly 20,000US\$) per year or less.

${ }^{3}$ Compared to these younger cohorts, the impact is far more modest and limited among older age groups. In $1998,81 \%$ of workers in age $45-54$ still had regular full time jobs. The ratio declined some since then and stood at $75 \%$ in 2006.

${ }^{4}$ The broad base of the manufacturing itself also eroded as many sectors within manufacturing lost its shares and the competitive edge. As of 2006, only three sectors, general, electric, and transportation machinery, dominate the manufacturing sector: its GDP share now stands at 13.3\%, more than a half of the entire manufacturing, whereas in 1990, its combined share was $11.4 \%$, about one third of the total manufacturing.
} 
to the factor immobility. The growth deceleration was not a simple outcome of poor performance of technology development. It was as much an outcome of sluggish factor mobility.

The apparent rigidity of the core employment, the rapid increase of the noncore employments, drifting Beveridge Curve, and stagnant productivity shape the landscape of the Japanese labor market today. This paper offers an interpretation of these key facts based on a model of competitive search. Our model analysis highlights the interaction of worker mobility with training cost and productivity shock. We assume that jobs in each industry faces an idiosyncratic and permanent negative technology shock. Crucially, we assume that some of the skills are lost by moving across different sectors in the economy and worker mobility requires re-training.

The model economy is populated with workers with different degrees of trainability. If the cost of re-training is relatively small, worker will be highly mobile. They quit jobs as soon as these jobs are hit by the negative productivity shock in order to search for a new job with higher productivity. Workers with somewhat higher costs of training decide to retain the current job after the shock, whereas once they lose the job, they move out of the depressed sector and try to search a job in a different sector. A group of workers with even higher costs of re-training may well give up mobility and cling to the job and the skill they have: they remain in the depressed sector even after they become unemployed. We show that the group of workers with highest training cost actually never take up jobs that require training. They spend their entire work life moving from one simple job to the other. Thus the model demonstrates that the worker allocation across types of jobs according to their trainability and shows that the degree of specificity and cost of training can explain the heterogeneity and over all compositions of worker mobility.

In order to make precise the relation between the stagnation in productivity and shrinking core employment, we inject macro shocks in terms of the changes in the magnitude and the frequency of idiosyncratic negative productivity shocks. Our model reproduces the major stylized facts we introduced in the beginning. We show that both long run unemployment and vacancy rates increase, and also that the share of the non core employees increases. A comparison with a hypothetical economy with lower cost of re-training will show that the combination of heavy relation specific investment and macro technology shocks are responsible for the sluggish labor adjustment and stagnant labor productivity. Moreover, using a calibrated example economy, we show that the time needed to absorb macroeconomic shocks are highly heterogenous across types of jobs and workers. In particular, the calibrated model will demonstrate that the share of simple jobs some take extremely long time to absorb the impact of the shock. The adjustment speed to the new steady state is essentially limited by the speed of retirement and entry to the labor market. This is consistent with slow but steady increase in the share of temporary and part time workers.

Finally, we conduct a set of policy simulations and asess the impacts of a variety of subsidy programs on employment, job creations, and training. We find that most of these programs have the strongest impact on subset of workers with relatively high training cost seeking a job that requires training.

In what follows, we first review and consolidate major findings taken from a fairly sizable body of empirical works on the Japanese economy during the lost decade (and its aftermath), especially those on the labor market (section 2). We will set out a simple and highly stylized model of the Japanese economies ca. 1990, and ca. 2006, and suggest how these two can be connected through injection of macro shocks to the system. The model economy and macro shocks are given concise representations 
in the model developed in section 3. The formal presentation and the analysis of the model are relegated to Appendix. Section 4 puts the model to work to explain the impact of the great recession and its lasting impacts. We conduct a simple calibration exercise to pin down the parameter values of the model. Our primary purpose is not to offer full fledged structural estimate of the model. Instead, our focus is on the mutual consistency in the behavior of key variables. Calibrated long run model is used to conduct policy simulations. Section 5 concludes.

\section{The Lost Decade and its Aftermath}

This section reviews what we have learned about the lost decade and its aftermath in the labor market by drawing upon the past empirical studies on the lost decade. Since the focus of the subsequent analysis is on the longrun structural changes, our focus in this section is also on the structural changes and their underlying factors. In the first sub-section, we focus on the sources of technology and relative price shocks which we model in Section 3. In the next sub-section, we focus on how the labor market responded to these shocks. In the last sub-section, we summarize major changes and constants.

\subsection{Reallocation and productivity shocks}

The lost decade was not only a period of "great recession", but it was also a period riddled with major productivity and allocation shocks. We highlight three major shocks: exchange rate appreciations and subsequent rise in outsourcing and imports, IT revolution and its impact on the employment, and the increase in the dispersions of TFP.

\subsubsection{Large swings in real exchange rate after 1985}

Effective real exchange rate jumped after the Plaza Accord in 1985. With several major swings, the 1990's was the decade of unprecedented fluctuations in real exchange rate. According the Bank of Japan, the effective real exchange rate was 116.2 in January 1990, and started to climb up rapidly and hit the historical peak in 1995 at 162.5 and remained at unprecedented high level until around 2000. As is well documented now, the long expansion from 2002 til 2007 was due in large part to the surge of the export aided by long downward swing of the real exchange rate: starting from the high of 143.8 in 2000, the real exchange rate depreciated by $37 \%$ to 91.2 by late 2007. This major swing and stagnation in the domestic market prompted Japanese firms to relocate their production facilities overseas, especially in Asia, the United States and Europe. Yen appreciation after the Plaza Accord also increased the share of imported intermediate and final manufacturing products. To illustrate the magnitude of the changes, note that the share of the final goods in the total import was only $31 \%$ in 1985 , and, then, the ratio rapidly increased to reach $62.2 \%$ in 2002. Imported price index also exhibited dramatic decline in 1990s. In mid 1985, the index stood at 164, then plunged below 100 by late 1980s. The index remained within the 90-100 range throughout much of the recovery. Major manufacturers started outsourcing their intermediated goods and parts first in Southeast Asia and United states, then to Europe and China. The stagnant domestic market demand and depreciation of real exchange rate starting from 2000 caused the second wave of changes. The recovery was earned mostly by sharp increase in exports, especially to the United States and China.

Taken together, large swings in exchange rate acted as a major relative price shocks to the producer of the tradable, which in turn induced outsourcing of the parts and intermediate goods. The waves of globalization have left visible impacts in 
the labor market primarily through the process of 'restructuring'. About a decade after it started in the US, Japanese media began reporting that Japanese jobs are destroyed by cheap labor in China. ${ }^{5}$

\subsubsection{IT Revolution}

The lost decade was also the period of an unprecedented change in information technology. IT revolution directly reshaped the landscape of the competitiveness in the international markets of manufacturing, telecommunications, and software industry. It also had important impacts as an input for virtually all segments of the economy. Given the rapid pace of internet technology diffusion, it is undeniable that IT revolution did have important impacts on workplace in Japan. Internet mails (to some extent) substituted for lengthy meetings in smoke filled rooms, grocery stores quickly adopted sophisticated POS system to record daily transactions. Many case studies do find impacts of IT technology adoption on work organization, micro productivity, time use, and other dimensions of daily work.

Contrary to earlier anticipation of great waves of new IT firms and growth in hiring, however, recent studies by Anton Braun et al. (2006) and Miyagawa et al. (2006) both found that the short run response to (positive) TFP shocks tend to reduce labor inputs ${ }^{6}$. Nishimura and Minetaki (2004) finds that the impact of IT use on productivity in Japan is extremely low compared to the United States, especially in the computer software industry. They also find some evidence that the IT technology substituted for the human capital accumulated by work experience and training. Miyagawa (2005) also finds that the industries invested heavily in IT reduced the employment share. As a result, much of the contribution by investment in IT on aggregate TFP was cancelled out.

Unfortunately, none of these studies cover the period prior to 1990s. Thus it is difficult to tell if the finding is due to the specific period of low labor immobility, or something more structural and applicable to other periods. It is at least safe to say that the overall labor market response to the IT revolution was weak and possibly perverse. Job creations due to new IT start-ups were limited, and industries invested heavily in IT reduced its employment shares.

\subsubsection{Overall decline and increased dispersion in TFP growth}

The breakdown of industries according to respective contribution to aggregate GDP growth shows that relatively even distribution of industries up until 1980s. Namely, majority of industries maintained positive GDP growth and contributed to the overall GDP growth. The pattern changed rather dramatically during the lost decade: by early 2000s, only a handful of sectors had positive contribution to the overall GDP growth, and the bulk of GDP growth is attributed to only two sectors.

The increased dispersion is found also within industry TFP growth. Fukao and Kwon (2006) find the widening of the gap in TFP across firms within industry. Since the gap widened in large industries, the average gap in the manufacturing sector overall also increased. Moreover they find that the widening occurred after 1997, and they find: "Across industries, widening gaps were found mainly in industries with a high R\&D intensity and where the internationalization of firms is more advanced." Surveys of the TFP growth studies show that most of them agree with Fukao and Kwon that the manufacturing sector TFP growth declined more than the service sector. Shinada (2003) reaches a similar conclusion in his study using the Development

\footnotetext{
${ }^{5}$ See two papers by Fukao and Kwon (2006) and Fukao et al. (2008)

${ }^{6}$ Miyagawa et al. (2006) argue: "The result indicates that real inflexibility in the labor market contributes to the negative response of the labor input to the technological shock in the short run."
} 
Bank of Japan data base.

\subsubsection{Increased Turbulence}

In sum, these quick tour of the empirical studies on major shocks in the1990s show that it was the period of increased turbulence which called for rapid shifts in resources: exchange rate swings, increased competition in the retail markets, and rapid technology changes and emergence of newly industrialized Asia. These changes induced de-coupling of production processes and it became common for major Japanese manufacturers to shift major production facilities over seas.

\section{$2.2 \quad$ Factor specificity and immobility}

\subsubsection{Sluggish labor adjustment}

Employment 'rigidity' can be defined in more than one ways. In most of the empirical studies, rigidity is mostly defined in terms of the speed of adjustment. Given the economic function of labor or other factor of mobility, employment rigidity refers to the sluggishness of labor mobility in response to various measures of productivity/profitability/wage differentials. In earlier empirical studies, the focus was distinctively on macroeconomic ones employing mostly macro time series data. They found adjustment of employment or total labor inputs towards hypothetical steady state or 'equilibrium' level is slow, at least in comparison with the comparable estimate for the United States. ${ }^{7}$

With the increased use of micro data starting in early 1990s, several types of rather different studies tend to suggest that the economy during the lost decade suffered from the sluggishness of labor adjustment and immobility of other factors. By linking job creations (destructions) by new establishments (closures) to the financial performance of the firm data, Fukao and Kwon (2006) finds that exiting firms have on average higher TFP than those entering. Genda et al. (2008) on the other hand, finds continued increase in job destructions during the lost decade, matched with mirroring declines in job creations. They argue that the depressed labor mobility, especially those with previous work experience, runs counter to what we would have expected if the lost decade was also the decade of restructuring. Genda et al. (2008) thus concludes that cyclical macroeconomic shocks shaped the pattern of job creations and destructions. This view is to some extent shared by a study by Fukao et al. (2008) who finds that as late as 2006, exiting firms have higher TFP than those surviving and it is attributed to the causal relation of recovery in TFP to restructuring. Namely, modest recovery in firm level TFP growth in the current decade is due largely to restructuring. Since TFP recovery due to restructuring enhances TFP by the reduction of employment and capital, the impact of the macro TFP can be often even negative. Although these studies disagree as to what extent the latter half of the lost decade was the time of restructuring, they all suggest that the labor mobility induced by productivity difference was weak at best, and the response of the stock variables, such as employment and unemployment are sluggish.

Kato and Kambayashi (this volume) employs micro data taken from the employment structure survey and find that job retention rate of the core employees (middle aged male workers with 5 or more years of tenure) remain largely unchanged even in the 2002 survey, although they also find clear and sizable decline in the job retention rates for the "expansion member" of the Japanese employment system, namely, female and employees at medium or smaller scale firms. In short, core of the Japanese

\footnotetext{
${ }^{7}$ Muramatsu (1995) surveys the empirical literature on employment adjustments in Japan uo to the early 1990's.
} 
employment system remains largely intact. At the same time, the higher productivity of the core employment is maintained by reducing its size.

\subsubsection{Cohort effects}

Another strand of research focused upon 'cohort effects' on employment, earnings and other key variables, and they ${ }^{8}$ unanimously find strong and persistent effect of cohort effects: i.e., macroeconomic situation in the year they enter the labor market have long lasting and quantitatively large impacts. This is at least consistent with the view that labor mobility is severely limited after their first job. The strong cohort effect can be explained in terms of relatively heavy investment in relation specific human capital in the beginning of the work career. If you miss this crucial timing either because of the failure to land on a career job after school, or because of the quits in the mid-career, this will have lasting impact on the future prospect. Those finishing school in recession years have smaller chance to land on tenure track jobs, or face severe competition for promotion within a firm. The aggregate outcome is the visible and lasting impact of the labor market fluctuations in the year they finish school on the rest of their lives. The impact of cohort effect is found especially large for non-college graduates. Assuming that it is more costlier to train those without, than those with college educations, this finding is consistent with the view that the importance of early investment (or the lack thereof) in training is responsible for limited mobility of workers in mid-career. Available evidence suggests that net gains from quits in mid-career was lower, not higher than before during the lost decade ${ }^{9}$. Related to these studies is the rapid increase in temporary and part time workers as we noted in Introduction. Due at least partially to the deregulation of employment matching business for profit, and partial lifting of prohibition of dispatched workers, temporary workers dispatched from those new firms increased rapidly. The survey of these workers indicate that they are less educated and they choose part time or temporary jobs primarily because they could not find regular full time jobs. Studies also indicate that the probability of landing on regular, full time jobs rapidly declines with age and continued experience of these marginal jobs. ${ }^{10}$.

Given the stop-gap nature of many temporary and part time jobs, the non-core jobs are significantly less stable and turnover rates, the average turnover rate is twice or more of the average turnover rate of the core employment, as shown in Figures 2 and 3. The rapid increase of temporary and part time employment generated a large composition effect which is primarily responsible for the drifting Beveridge Curve in Figure 1.

\subsubsection{Decline in labor share}

In spite of the recovery and longest expansion in history, wage compensations actually declined after the peak, around 1997. After 18 years since the burst of the bubble, the average real wage rate is still lower than it was in 1990. The dismal record is partly due to composition effect as the average wage rate for the non-core employees is only $70 \%$ of the comparable regular full time workers. But it is not the whole story. Even for the regular full time employees, the average real wage rate declined more than $7 \%$ during the last ten years, and only $6.6 \%$ higher than 1990 figure. The unemployment rate did decline after 2002 from the historical record of $5.4 \%$. But the seven years of the recovery only succeeded in cutting less than a half of the increase

\footnotetext{
${ }^{8}$ Recent studies include Kondo (2007) and Ohtake (2005).

${ }^{9}$ See for example, Part II, Chapter 2, Section 3 in :Ministry of Welfare and Labor (formerly Ministry of Labor), 2004, White Paper on Labor (Rodo Hakusyo)

${ }^{10}$ See Genda and Kurosawa (2001), and Esteban-Pretel, Nakajima, and Tanaka (2008), and Genda, Kondo and Ohta (forthcoming)
} 
since 1990. As of 2007, the unemployment rate was $3.9 \%$, almost the twice of the unemployment rate in 1990.

\subsection{Structural breaks and constants in the labor market}

As the Japanese economy finally emerged out of the decade long stagnation around 2002 , the labor market was still in the midst of absorbing the shocks. It was only in 2003 to 2004 that the unemployment rate started to decline, and hiring of new school graduates picked up. Then, a simple question which is not easy to answer is: do we see the Japanese labor market after 15 turbulent years as the one essentially unchanged from the prototype employment system of the post war era, or has anything changed fundamentally? Let us start with what apparently has not changed.

\subsubsection{Constants}

Using the most recent micro data, Kato and Kambayashi (this volume) find some weakening of the employment security for the core workers in the latter part of the lost decade. Investments in firm level training seems to have declined, but we lack any hard evidence ${ }^{11}$. The system and its crucial function of the recruitment of new school graduates have not changed. It still is by far the most important means for hiring new workers. Significant gaps remain between the regular and full time versus the rest of employees in compensation, stability, training and promotions inside the firm. There is no evidence indicating a major change in the overall sluggishness of employment adjustment. Together with the use of temporary workers, work hour adjustment is still predominant in adjustments in total labor inputs.

\subsubsection{Changes}

It seems fairly clear that we see more of continuations, rather than any significant breaks in structural and organizational characteristics surrounding the Japanese labor markets. There are important changes, however, and they prove to be important for the subsequent analysis and the model based characterizations.

First of all, even if the core of employment system remained largely intact, it is undeniable that the size shrank, and continue to shrink, as can be seen most easily by the steady increase in non-core employment.

The lost decade was the period also of depressed metabolism of the economy overall, and labor market is no exception. Of special importance is dwindling rate of start-ups and hence job creations by entry of new firms ${ }^{12}$. There has been some weak recovery in the last few years, but, even that is way too small, even after taking account of the weak over all recovery of the economy.

If there is anything genuinely new in the labor market, they are found on both ends of the quality spectrum of the Japanese labor. At one end, we find the emergence of enclaves of specific jobs where the external labor market is the dominant venue through which qualified people are matched to jobs. Such markets are now found in some of highly skilled professionals: examples include IT related jobs, such as SE, web designer, CG specialists, etc, etc. As we have noted already, we see the rapid growth of temporary and part time workers at the other end.

\footnotetext{
${ }^{11}$ A group of economists including one of the co-authors of this paper conducted a survey of employees at auto assemly plants in Japan. The survey indicates the heavy investment in training, averaging 80-100 hours per year in on the job training alone, which is far larger than 40 to 80 hours per year per participants found in Bassanini et al (2007) found for major OECD countries. See Airga, Kurosawa, Ohtake, and Sasaki (2009).

${ }^{12}$ See Genda et al. (2008) for relevant data. The establishment start up rate was around $6 \%$ during 1970 s and early $1980 \mathrm{~s}$. The decline of the start-up rate have been continuing since the latter half of 1980 s until now. The last 5 year average is $3.1 \%, 1.4 \%$ below the destruction rate.
} 
For different reasons, both ends of labor are substantially more mobile across firms than those in the middle. The emergence of external markets for professional jobs reflects to some extent the failure in 1980s by large Japanese firms to internalize these professional skills ${ }^{13}$.

This reflects the changes in workplace that occurred during the last 20 years or so. Some of junior level clerical workers are no longer found in Japanese offices ${ }^{14}$ : The majority of them are now outsourced and partially substituted away by PC and the use of other IT technology. Having observed early failures of internalizing some professional positions ${ }^{15}$, many firms perhaps decided to rely on either contractual outsourcing or specialized subsidiaries to handle IT related tasks. We also find some evidence showing some professional positions in the finance sector are filled by the use of head hunters and rely almost exclusively on mid career quits.

To sum up, we do see some important changes. As far as the factors related to the limited labor mobility are concerned, however, no compelling evidence exists that the Japanese economy underwent major structural change.

\section{The Model}

This section presents the model of competitive search. We relegate formal presentation and the analysis to the Appendix. In this section, instead, we focus on the characterization of the equilibrium and demonstrate that the model captures the key observations assembled in section 2 .

\subsection{Focus}

In Section2, We highlighted three key characteristics of the Japanese labor market.

1. Intensive investment in relation specific (human and physical) capital. This is apparently responsible for the relative immunity of the core employees.

2. Limited worker mobility. Worker mobility is largely limited to at most the first ten years since their entry to the labor market. The first jobs are particularly important. This is partially a consequence of fact 1 above. As a result, many empirical studies find statistically significant and sizable cohort effects on employment probability, job security, and earnings.

3. Complementary to the market for the core employees, there exists highly flexible market for temporary and part time workers.

Against these constants of the labor markets, the lost decade have brought about three important changes.

1. Shrinkage of the core employment.

2. Outward drift of the Beveridge curve.

3. Stagnant job creations and productivity growth

In what follows, we offer a model that captures these key characteristics and changes in the Japanese labor market.

\footnotetext{
${ }^{13}$ See Ariga, Brunello and Ohkusa (2000). See also Kato and Kambayashi in this volume for the decline of job retention rate for "expansion members" of the Japanese employment system.

${ }^{14}$ It is symbolic of the change that the Japanese word 'office lady' ,- often abbreviated as OL, referring to women at office working primarily as secretaries or lower level clerks -, almost completely disappeared from the daily conversation.

${ }^{15}$ Recall many troubles in integrating the computer systems after mergers of major city banks. They revealed that the "legacy" of the system is extremely costly to undo.
} 


\subsection{A model of competitive search}

Against these background and stylized features of the Japanese labor market, we employ a variant of competitive search as our basis of the analysis ${ }^{16}$. Here, we describe the major features of the model without technical details.

We consider unit sized mass of population. We assume that each worker retires from the labor market at the rate $d$ per unit of period. The labor force is held constant by the equal amount of net inflows into the market. Each worker is endowed with distinct trait which determines the cost of training. We denote by $z$, the cost of training incurred when each worker is trained for the first time at a job that requires training. The variable $z$ is a random draw from the cumulative distribution, $F(\cdot)$. We assume away any changes in individual worker's $z$ until the retirement. Job searchers and vacancies are matched through search initiated by workers. Only the unemployed workers search. Specifically, each worker contacts a vacancy at a fixed probability per unit of period. Workers can pinpoint the search in such a way that he can choose the exact type of vacancy he will apply to. The essence of the directed search is that each worker has full knowledge of offers posted by vacancies. The firm must post employment offers in order to recruit the worker. We assume that the jobs post all the payoff relevant details of the employment contract. Moreover, they are all endowed with unlimited ability to commit to the posted contract.

Crucially, we require each job slot to choose a specific point in the continuum of "industry", a mnemonic to distinguish technology embodied in each job slot. Once installed, all the jobs are totally immobile. We assume that this continuum to expand continuously over time. The idea is that a specific job is based upon installed technology and jobs are totally immobile. The technology is public goods so there is no limit to the use of any specific industry. Arrivals of new technology is represented by the ever expanding continuum. Each industry faces the probability of negative productivity shock. The shock permanently lowers the job productivity. Hence the 'state' of the industry is either 'good', or ' depressed', depending upon if the shock already occurred. With these assumptions, we model the shock to be permanent and common to all the job slots in the same industry. Aside from 'good' or 'depressed' state, all the industries are homogenous so that at equilibrium the new start ups of job slots are evenly spread in 'good' industries.

Each job slot can choose the industry and type of job slot, and make the wage and employment contingent on the state of industry. That is, the firm can offer a contract that pays the worker different wage according to the state, or make the employment contingent upon the state. Firms can commit the type of workers which they would employ. By this assumption, we can divide the market into the continuum of sub-markets indexed by worker type $z$. In each sub-market, there are homogeneous workers and job slots. The worker can direct their search target to the job which gives the highest expected return. If there is more than one jobs with the same

\footnotetext{
${ }^{16}$ We believe, for our objective, the model of competitive search is a better choice, than a random matching model. For one thing, in a random matching model, mismatches occur as an inevitable outcome of matching technology. The nature of random matching is also highly misleading if it is applied to the market for the market of school leavers in Japan. The implication, that a new college graduate ends up in a job that he never wanted because he could not choose where to apply, seems difficult to justify.

Also for the analytical tractability, a random matching is a poor choice in our case. Such a model will be practically unmanageable with up to six types of employment and unemployment (state variables). Under random matching models, vacancy shadow prices will be weighted average of values associated with respective match combinations, which render the dynamics practically intractable.
} 
highest return from the search, workers randomly choose a job among these offers ${ }^{17}$. The end outcome of competition among job slots is that only those jobs offering the market determined (highest) expected returns can attract (any number of) job searchers. In other words, at such equilibrium, individual firms and workers treat as given the expected returns from search and each job slot believes (correctly at equilibrium) that it can attract as many expected number of applicants as it wants as far as their posted contract provides each applicant with the market rate of expected return from application.

Consider a typical sub-market. Denote by $\psi\left(\frac{U}{V}\right)$ the probability that a vacant job slot receives at least one application, assuming there are $V$ equally attractive vacancies and there are $U$ equally qualified job searchers. We assume this probability is strictly increasing and concave in its argument. Then the total number of matches per unit of time is given by

$$
m(V, U)=V \psi(x)
$$

which is linear homogenous in $V$ and $U$. Denoting the ratio of the job searchers to the vacancy by $x$, the probability for a searcher to be matched to a vacancy is given by

$$
\phi(x) \equiv \frac{m(V, U)}{U}=\frac{\psi(x)}{x}
$$

Henceforth, we call $x$ as the queue length (the number of job searchers per vacancy).

\subsubsection{Two types of jobs}

We assume an economy wherein production technology is embodied in each job slot as it is created. With instant and free access to any technology for a newly created job, zero profit condition for job slots always hold.

Denote by $\rho$ the probability of shock per each period. If a job slot is hit by a shock, its productivity is reduced to $\theta(<1)$ of the output before the shock and it will remain at that level forever ${ }^{18}$. Henceforth we call the collection of jobs with permanently lower productivity as $d$-sector, in contrast to $g$-sector where jobs are yet to experience such shocks. Namely, $d$-sector collects all the jobs located in the depressed industries. Given the symmetry of industries which are all held implicit in the model, each industry in $g$-sector has the same size and they are indistinguishable. The same holds true for industries in $d$-sector.

To highlight the key heterogeneity among the types of employment, we consider two types of jobs. Each job slot can be occupied by a single worker. We represent the non-core employment by type $s$ jobs which requires no training and any worker can be employed to produce the same $q^{s}$ units of (homogenous) output per period of time. Each type $s$ job slot can be instantaneously and costlessly created but it $\operatorname{costs} p_{s}$ per period to maintain with or without a worker in place. Destructions are automatic and instantaneous if they stop paying the cost. On the other hand, type $c$ jobs require investment in training and more productive, i.e., $q^{c}>q^{s}$. For simplicity,

\footnotetext{
${ }^{17}$ Importantly, we assume that workers cannot coordinate among them which specific job slot to apply if there are more than one job slots offering the identical expected return. This inability to coordinate application strategy is the essence of search friction in this type of models.

${ }^{18}$ The idea is that installed jobs runs the risk of being left behind as newer technology arrives to the industry they reside. Rather than modeling explicitly the productivity growth of new technology, we model such technology shock affecting negatively the relative position of the existing jobs. This shortcut simplifies the model greatly, but, interested readers should consult Mortensen and Pissarides (1998) and Hornstein et al. (2007) for explicit modeling of technology advancement in search theoretic models.
} 
we assume that it takes once and for all investment by the amount $z$ to train a worker who has never received any kind of training before, or, $\epsilon z$ if he has been trained at a different firm ${ }^{19}$ in the same industry, and $(\epsilon+m) z$ if he received training in the past at a firm belonging to a different industry ${ }^{20}$. We assume

$$
0 \leq \epsilon \leq \epsilon+m \leq 1
$$

so that at least some part of the initial training is useful even if workers are employed at different firm or industry. We also denote by $p_{c}\left(>p_{s}\right)$ per period rental cost of type $c$ job slot.

Finally, we assume that exogenous separations occur in either type of jobs and denote by $\delta_{i}$, the probability per period that such separations occur within each period.

Notice that the specification above incorporate varying degree of transferability of skills across jobs and industries. Since workers are always free to apply for any vacancy (provided that they meet the specified qualifications as detailed below), the mobility of workers are made endogenous. In particular, workers without any previous training is perfectly mobile because he has not sunk any investment in training. This mobility reflects not only the nature of training costs as specified above, but it also reflects the nature of competitive search: the mobility is ensured by the assumption that a worker can pinpoint the job offer he applies ${ }^{21}$.

\subsubsection{Constrained social efficiency of competitive search equilibrium}

The market equilibrium mediated through competitive search is known to be constrained socially efficient: the market allocation maximize the net social surplus, given the matching and production technology. Intuitively, the efficiency of the equilibrium can be understood by a simple analogy of the competitive search to a perfect competition. In the latter, all the participants take as given the equilibrium price and maximize their expected utility. The marginal conditions ensure the optimality as the equilibrium price equates (locally non-increasing) marginal benefit for the buyer to the (locally non-decreasing) marginal cost of output. In the competitive search equilibrium, job searchers and vacant job slots take the expected returns from job search as given in the market and maximize respective surplus. The constrained efficiency is ensured by the equality between marginal (and non-increasing) gains in the probability of match (and production) to the opportunity cost (i.e., applying to the other jobs). The joint outcome of these decisions generate allocation identical to that of social planner because expected returns from search acts as the price at which each job slot can attract as many expected number of applicants as possible. Search friction transforms competitively priced input (the expected number of applicants) into the probability of match and output (and hence profit). This transformation is determined completely by matching technology and it is strictly increasing and

\footnotetext{
${ }^{19}$ We ignore the measure zero probability of being matched to the same job slot where he received the previous training.

${ }^{20}$ Notice that the formulation accommodates various special cases. For example, if $m=0$, the training contain some firm specific element but it is general across industries. $\epsilon=0$ on the other hand corresponds to a case wherein training produces human capital shared by all the firms in an industry. A completely firm specific human capital implies $\epsilon=1$ so that none of the previous trainings are helpful outside the firm they are trained.

${ }^{21}$ This is an extreme but useful property of the competitive search. Given the time and money school leavers and the firms invest in the market for new school graduates, conventional model of random matching seems ill fit as the nature of the friction in the market. After all, random matching assume that workers cannot choose the type of jobs they apply. In this sense, immobility is due to matching technology. Needless to say, mismatches due to information imperfection do exists even in the markets for the new school graduates, but they are not central to the issue of labor immobility.
} 
concave. The outcome of this maximization on the both sides of the market is the first order optimality condition which ensures the efficiency.

In our current model, we added inter-temporal element with irreversible investment. This does not alter the fundamental property of the efficiency of the equilibrium in that we allow the job slot to commit to posted offer which can specify in full all the contingent elements of pay and employment. ${ }^{22}$

\subsubsection{Market equilibrium}

At the market equilibrium, each worker (and the corresponding search market) is indexed by the cost of training and work experience. Consider a typical group of workers whose training cost level is $z$. If a worker has never been trained before, his choice is to apply to a type $s$ job or a type $c$ job without requirement for any prior training. The market equilibrium value of such offers from type $c$ jobs can be denoted as $U_{g}(n, z)$ wherein $n$ as the first argument in $U_{g}$ signifies he has never been trained at any firm before. Subscript $g$ signifies that the job is in good industry. No jobs in depressed industry can offer that matches the offers from good industry hence ignored. Since the type $s$ job does not require any training, its equilibrium offer is independent of $z$, so we may denote this by $U_{s}$. Hence his best choice is simply

$$
U(n, z)=\max \left[U_{g}(n, z), U_{s}\right]
$$

As higher training cost reduces the joint surplus at type $c$ jobs, $U_{g}(n, z)$ is decreasing in $z$. Thus there exists a threshold value of $z$ such that untrained workers choose type $c$ job if and only if her training cost is equal to or lower than $z^{s}$.

Given the stationarity of the economy as well as individual worker's life, a worker's optimal choice of job at equilibrium is also stationary and it depends only upon her training cost and work experience. Specifically, it is evidently optimal, for a worker exogenously separated from type $s$ job, to resume searching for a type $s$ job again because type $s$ job does not offer training opportunity nor is it required. Since a trained worker costs strictly less to retrain, a trained worker never apply to a type $s$ job. Hence the decision to search for a type $s(c)$ job is final and they will continue to do so after exogenous separations. In other words, type $s$ is a dead end job.

For a worker separated from type $c$ job, his job search will be different from those without prior training because his training cost at a new type $c$ job is either $\epsilon z$ or $(\epsilon+m) z$, depending upon whether he remains in the industry where he received the training in the past. Again, their choice is completely characterized by respective value functions, $U_{i}(g, z), U_{i}(d, z)(i=g, d)$ wherein subscript $i$ signifies the sector in which a worker searches for a job. If the industry he is trained in the past belongs to $g$-sector, there is no need to move to a different industry where a larger re-training is needed. On the other hand, if the industry he received training is now in $d$-sector and productivity of jobs are lower, it might make sense to move out of the industry and search for a job in $g$-sector. In Appendix, we prove the following

\footnotetext{
${ }^{22}$ Note that this is certainly not meant to deny the possibility that some types of competitive search with training can generate inefficient allocation. For example, if a job slot cannot commit to a contingent contract and chooses the action which is ex post optimal after the shock, such an equilibrium may entail inefficiency. See subsection 4 in Appendix. In short, the market equilibrium with competitive equilibrium in our paper is an exact analogue to Arrow Debreu model of general competitive equilibrium.
}

Another note on the wage schedule. Since employment continues more than one periods, competitive search can be supported by more than one types of wage offers provided that the expected present value of the offer is the same. See appendix for the details. 


$$
\begin{aligned}
& \frac{\partial U_{g}(d, z)}{\partial z}< \frac{\partial U_{d}(d, z)}{\partial z}<0 \\
& \exists z^{u} \text { such that } \\
& U_{g}(d, z) \gtrless U_{d}(d, z) \\
& a s \\
& z \lessgtr z^{u}
\end{aligned}
$$

Namely, the impact of training index $z$ is smaller if she stays in the same sector than if she moves out to a $g$-sector, i.e., $U_{d}(d, z)$ is flatter than $U_{g}(d, z)$. This makes sense because if she moves out, re-training cost is $(\epsilon+m) z$, whereas if she stays, it costs only $\epsilon z$. Thus the dependence of her value function on training cost is proportionately smaller if she stays. If the training cost is sufficiently small, it is evidently optimal to incur re-training cost and move to a industry in $g$-sector where jobs are more productive. Thus there exists threshold $z^{u}$ such that those with training cost lower than the threshold will move out of $d$-sector. The remaining question is what if the worker is employed when the job is hit by the productivity shock. The optimal choice is again characterized by yet another threshold, $z^{e}$. If the training cost is smaller than the threshold, it is optimal to terminate the employment and move to $g$-sector and search for a job. Since her value of being employed is higher than being unemployed and searching for a job in the $d$-sector, we have

$$
z^{e}<z^{u}
$$

Consequently, three thresholds completely characterize the competitive equilibrium in each market indexed by $z$.

\section{Figure 5 around here}

Figure 5 summarizes the discussion above in the context of the formal presentation of the equilibrium in Appendix. The figure takes the cost of training $z$ on the horizontal axis, and on the vertical axis we take the value of the contracts at the equilibrium. Given the future probability of negative productivity shock, the contract offer contains contingency in the event of the shock. First, notice that the value of type $s$ contract $\left[U_{s}\right]$ is a horizontal line since the job does not require any training and the output is the same irrespective of $z$ or previous training. The first threshold, $z^{s}$ is the point where the value of type $\mathrm{c}$ job offer to untrained worker $\left[U_{g}(n, z)\right]$ cuts the horizontal line. Thus workers with training cost smaller than threshold search for a type c job. The decision on mobility after the shock is an outcome of competition among offers with different contingency. Note that this decision concerns only those with previous training. Untrained workers can move costlessly across different submarkets so they never stay in industries hit by the negative productivity shock.

Then, suppose a worker has previous training and have been searching for a job in the industry when the industry is hit by the negative productivity shock. Whether or not he should search in the same industry or move out depends upon the two value functions, each representing the stay or move. Since this decision is relevant to the group of workers who chose unconditional employment contract and retained the job after the shock but later separated from the job for exogenous reasons, this decision is equivalent to whether or not an offer with unconditional employment contract that stipulates after shock $\left[\tilde{U}_{\bar{g}}(d, z)\right]$ has higher value than the offer available for the trained worker in $d$-sector $\left[\tilde{U}_{d}(d, z)\right]$. Thus the second threshold, $z^{u}$, is given by 
the intersection of the two value functions. Finally, consider if an employed worker should retain the job when the productivity shock occurs. In terms of competition of offers, this is tantamount to the comparison between the offer with unconditional employment $\left[\tilde{U}_{\bar{g}}(d, z)\right]$ and the one that stipulates separation at the moment of the shock $\left[\tilde{U}_{\hat{g}}(d, z)\right]$. The intersection of these two schedule determines the last threshold, $z^{e}$.

\subsubsection{Worker mobility under three types of equilibrium}

For workers with training cost above $z^{s}$, they only apply for type $s$ jobs. While employed at a type $s$ job, he may be separated for exogenous reasons (that occur with probability $\delta_{s}$ ), retires (with probability $d$ ) or the job is hit by the negative productivity shock. Depending upon the configuration of parameters, either the job is destroyed and employment is terminated, or, the employment continues until separations occur for exogenous reasons ${ }^{23}$.

Workers with training cost lower than $z^{s}$ search for a type $c$ job. Their employment is terminated either by exogenous separations or by the retirement of workers. Upon the productivity shocks, we obtain three types of configurations. Those workers with training cost between $z^{u}$ and $z^{s}$ will remain in the same industry until their retirement, even when the industry is hit by the negative productivity shock. Thus workers are necessarily less mobile than type $s$ workers. Among workers in the next tier, i.e., those with training costs between $z^{u}$ and $z^{e}$, their mobility depend upon the timing of the productivity shock. If he is employed when the industry is hit by the productivity shock, he retains the job until he is separated by exogenous reasons. Once unemployed, however, she moves out of the industry now in $d$-sector and seeks a job in $g$-sector. Therefore this tier of workers are more mobile than the first tier. Finally, workers with the training cost lower than $z^{e}$ is the most mobile among workers who choose type $c$ jobs. They move out of the industry whenever it is hit by the productivity shock, even if they are employed at the moment of shock.

In sum, the model predicts the worker mobility is U-shaped across index of training cost: those with highest training cost actually never receive training and mobile, while workers with training cost below $z^{e}$ will always move after the shock.

\subsubsection{Zero profit condition and optimal queue length}

In appendix, we show that market equilibrium is characterized by the first order condition for the optimal queue length $x$, i.e., the average number of applicants to a job. For a population of workers with given training cost $z$, there potentially exists three types of offers for type $c$ job. One type of offer is for the untrained workers. The second is for those trained in a different job in the same industry. Finally, an offer to a worker who had been trained in a different industry. Note that the last group of workers must have been in a industry hit by the productivity shock. Otherwise, given the symmetry of the industry continuum, there is no reason to move.

\section{Table 1 around here}

In sum, there are potentially four distinct sub-markets each with distinct offers, depending upon whether or not and at where a worker is trained, as shown in Table 1. Let us start with job slots in $d$ sector. As we explained above, no worker moves

\footnotetext{
${ }^{23}$ Because this type of jobs do not require training, the optimal choice is the same for all the type $s$ jobs. Hence only one of the two possible cases is observed at equilibrium. It should be noted also that the surplus from employment is due entirely to the search friction and we should expect that job destructions and separations are more likely outcome in comparison with type $c$ jobs. In calibrated model below, indeed, all type $s$ jobs are destroyed after the productivity shock.
} 
to a job in the $d$ sector. If he is trained, there is no gain from moving into a industry with lower productivity. By the same reason, untrained worker has no reason to search for a job in $d$-sector. Consequently, the market is potentially active only for those who have been trained in the same industry already. As we have shown above, this segment is inactive if $z \leq z^{u}$. For a job in $g$-sector, two types of sub-markets, $(n, g)$, and $(g, g)$ are always active, whereas $(d, g)$ is inactive if $z \geq z^{u}$. The zero profit condition for each active sub-market uniquely determines the optimal queue length. By complementary slackness condition, there is no vacancy and the market is inactive if the zero profit condition is not binding.

\subsection{The Full Market Equilibrium and Impacts of Macroscopic Technology Shocks}

\subsubsection{The Full Market Equilibrium}

The full market equilibrium is determined by two sets of conditions. First set contains equations which jointly determine optimal queue lengths and corresponding values of employed and unemployed workers. The equilibrium is such that these sets of conditions do not contain state variables, i.e., levels of employment and unemployment with or without training. The equilibrium values of queue lengths for respective offers are used to obtain the values of offers, or, equivalently, the equilibrium value functions for unemployed workers for given training cost and the industry of the last training. They together thus determine "prices" that jointly support the efficient allocation of workers to queue and hence to jobs.

The sub block of the model corresponding to the value functions is determined completely within themselves, independently from the state variable dynamics. Since the dynamics of the value function block is totally unstable, the solution, or the market equilibrium is such that the equilibrium asset values are always at respective steady state values. Consequently they jump immediately to the new steady state values whenever the model is disturbed by a change in a parameter. State variables, namely, employment and unemployment evolve over time towards the steady state with the speed which partially depends upon respective value functions, the details of which are shown in Appendix.

\section{Figures 6-8 around here}

Worker mobility at the market equilibrium is depicted in the three diagrams shown in Figure 6 through Figure 8. Figure 6 shows the possible moves for the least mobile group, i.e., those with training cost between $z^{u}$ and $z^{s}$. The arrows from $g$ sector to $d$ sector indicate the changes induced by the productivity shock and the workers in this group never endogenously leave the job they are matched for the first time. Even if they are separated from the first job, they remain in the same industry. Figure 7 shows the moves for the middle tier of the workers in type $c$ jobs. Note the arrow from $u_{d}$ to $e_{g}$ indicating the move from the depressed industry to search for a job in healthy industry. Finally, the most mobile group is shown in Figure 8. They never stay in $d$ sector.

We now employ the model equilibrium to depict the major changes in the labor market from the onset of the lost decade until early years of the new century.

\subsubsection{Two types of shocks: increased turbulence and deeper impact}

Needless to say, conventional types of macro shocks must have hit the economy during the lost decade. After all, no one doubts that the economy experienced severe decline 
in the aggregate demand. To the extent that those shocks were cyclical, however, tracing out the impact of such shocks is not our main focus, thus we ignore them. It seems fair to say that at least two type of technological shocks also occurred during the period and both of them are likely to be permanent. The advent of information technology (IT) most likely shifted comparative advantages of industries and organization forms. Another important factor is rapid shifts in comparative advantages in the international markets. Large swing in real exchange rates, lower trade barriers, increased reliance on parts and intermediate goods from emerging East Asian countries, etc, all made the market more volatile. We model this increased turbulence as an upward shift in $\rho$. At the same time, rapid shifts in technology frontier made it more costly to retain and continue to use the current technology. We model this as a deeper impact of negative productivity shock to the existing jobs, i.e., lower $\theta$.

Although both types of changes reduce the overall efficiency of type $c$ jobs, they differ in their impacts on the labor market dynamics. To begin with, note that the endogenous labor flows in our model are driven by the mobility from $d$-sector to $g$-sector. An increase in $\rho$ increases the probability of technology shocks. At the same time, the higher probability of technology shock reduces the net productivity gains from this mobility because the expected duration of a job in $g$-sector is reduced. Thus moving from $d$ sector to $g$ sector generates smaller gains as the new industry is more likely then before the macro shock to become $d$-sector. Consequently, such a shift lowers the mobility after the productivity shock. Overall impact of the shock on labor mobility can be either positive or negative.

On the other hand, a decrease in $\theta$ does the opposite: the impact of productivity shock is larger so that the gains from the mobility is also larger. As a consequence, workers are more likely to move out of $d$-sector to search for a job in $g$-sector. Thus the labor mobility should increase as a result of the shock. Therefore, a combination of changes in these two parameters tend to reinforce each other in terms of lowering overall productivity of type c jobs (vis a vis type s sector), whereas the impacts on short run labour mobility may well cancel out each other. Since the overall productivity of type $c$ jobs decline, both types of shocks shifts the overall labor allocation away from type $c$ jobs and type $s$ positions will expand.

\subsubsection{Short run and long run impacts}

Suppose these types of shocks are totally unexpected and changes are also permanent. The immediate impacts of these types of shocks differ depending upon whether or not the impact is favorable to the $d$-sector employment or not. The asymmetry between the response to the two shocks reflect the search friction. Although existing employment can be destroyed immediately, an increase in employment can occur only through increased matching.

An increase in $\rho$ lowers the difference in values of $g$-sector and $d$-sector jobs as $g$-sector jobs are more likely to move to $d$-sector. In this case, an increase in employment at $d$-sector can occur only through larger inflows out of $g$ sector to $d$, and, or by increased matching at $d$-sector unemployment pool. In short, employment level at $d$-sector cannot jump. Consequently, shocks which favors the declining sector will move the economy only gradually over time.

On the other hand, a decrease in $\theta$ increase the value of $g$-sector jobs relative to $d$ sector jobs. Hence, for some type of workers, employment at $d$ sector is no longer the best alternative. Instead, they find it optimal to move out of employment and search for a job in $g$ sector. Thus the change will produce immediate job destructions and resulting move to unemployment pool for the trained (at $d$ sector) workers to $g$ 
sector $^{24}$. We would expect to have a spike in separation and accession rate. In other words, the model predicts that the decline in turnover rates should be gradual and long lived, whereas an increase tend to be more sporadic and rapid.

In the long run, both of these shocks reduce the overall surplus of type c employment, reduce the equilibrium queue length, and increase the steady state unemployment. The end result is outward shift of Beveridge curve and lower vacancy/unemployment rate.

\subsubsection{Long and persistent impacts}

The apparent sluggishness of the Japanese labor market in absorbing macroeconomic shocks has been the focus of the research for a long time. The development in the lost decade and its aftermath only made this characteristic more puzzling, given the severity and the length of the stagnation. The model developed in this paper represents overall mobility as the aggregate outcome of individual worker who differ in their trainability and their experience. We have shown above that a group of workers in type $c$ jobs with relatively high training costs are highly immobile. They are totally immobile across "industries". They cling to the skills they acquired in the previous job even after the industry lost its productivity edge permanently. For those jobs to disappear, the workers occupying these jobs need to retire. This makes the process of adjustment extremely slow. Unlocking employment relations with relation specific investment is costly for themselves as well as to the economy as a whole. On the other hand, it is misleading to project the aggregate outcome based solely on this group. By definition, this group is under-represented in the labor mobility data (because they do not move, at least not endogenously). The over all labor mobility, hence the time needed to absorb macroeconomic shocks, are the aggregate outcomes of heterogenous workers' individual mobility decisions, thus they are sensitive to the share of workers in terms of the trainability and work experience.

Needless to say, the impacts on worker mobility and income differ across individuals. The other side of relative immobility of trained workers is that the joint surpluses protect their jobs, while those jobless, especially those without training, take the blunt of the shock.

The available evidence suggests the lost decade was also the time when aggregate mobility diminished. Population composition was changing rapid and new entry to the labor market declined sharply. The distortions in the capital market which manifested so vividly during the last years of the century only contributed to decelerate the labor mobility. This impact was felt on both job creations and destructions. The decline in start ups is likely to have reduced the available new openings, whereas the survival of "zombie" firms contributed to the longevity of employment in depressed sectors above and beyond warranted under unfettered competition.

\subsubsection{Cohort Effects}

Two macro technology shocks, represented by changes in $\theta$ or $\rho$, shift the relative positions of value functions and hence positions of three thresholds. For example, suppose that $z^{s}$ threshold moves to the left after the shock, say from $z_{0}^{s}$, to $z_{1}^{s}(<$ $\left.z_{0}^{s}\right)$. Workers with training costs between $z_{0}^{s}$ and $z_{1}^{s}$ will have dramatically different mobility, depending upon the timing of the first employment. If a worker is lucky enough to get a job before the shock, she must have been employed at a type $c$ job and she must have received training, thus making her largely immune from the shock because her value function reflects the investment which is already sunk. On the other

\footnotetext{
${ }^{24}$ Notice that the opposite change cannot produce jumps in $d$ sector employment because employment can be increased only gradually through matching.
} 
hand, those who fail to be employed (strictly speaking, experience employment) at a type $c$ job before the shock now find themselves no longer needed in type $c$ jobs. Only jobs available now for them is type $s$ which offer no training. This impact is permanent and cannot be undone, thus leaving the visible scar to the work history of those cohorts.

Intuitions also suggest that this change occurs over an extended period of time. A worker who was lucky enough to jump into the boat of secure, life time job of type $c$ will live a life not very different from the one before the shock, and this situation lasts as long as he remains active. The economy soaks in the full impact only when those last lucky ones eventually retire from the labor market ${ }^{25}$.

\subsection{Summary and Limitations}

This section presented without technical details the essence of the model of competitive search. Our model captures some of the key findings on developments of the Japanese labor market since 1990s. Sluggishness of the overall response to the shock is modeled as the aggregate mobility of heterogenous workers with different training costs and work experiences. We highlighted the fact that for some of workers it is never optimal to move to a different job even if the current job is hit by permanent productivity loss. Our model equilibrium is consistent with the presence of strong cohort effects. We also have demonstrated that the combinations of shocks may cancel out each other on their impacts on short run mobility, even though they both increase the long run unemployment rate in the long run.

Before closing this section, we should note the limitations of our model as employed for the narrative of the Japanese labor market in the last 15 years. Our model cannot capture some of the key macroeconomic issues, which must have occupied the minds of policy makers during the lost decade, such as the fear of deflation spiral, or for that matter, any macroeconomic dynamics associated with price rigidity, market failures, etc. Needless to say, these concern shaped many of the policies which we analyze below ${ }^{26}$.

\section{Model Calibration}

\subsection{Steady State Equilibrium with benchmark specifications.}

We use the model outlined in section 3 to trace out the development of the labor market for the period 1991-2006. The model has 16 free parameters as shown in Table 2. Our strategy is simple. We pin down 9 of these parameter values by employing various sources of the past empirical studies. The remaining 7 free parameters are chosen to meet 7 empirical targets. We show our benchmark values of 16 parameters as shown in Table 2 . Below we have a brief description on how we set the value for

\footnotetext{
${ }^{25}$ The crucial point is that the training investment is sunk cost. Therefore, even if a second technology shock completely washes out the change in either $\theta$ or $\rho$ at the first shock, those training investment still have permanent impacts on the economy as long as they remain in the labor market.

${ }^{26}$ Another somewhat more subtle limitation is the price we have to pay in order to retain the analytical tractability of the model. In spite the complexity, the model equilibrium is fairly straight forward in implications. This relative clarity and sharpness of the model are bought by the competitive search and zero profit condition on vacancies. If we acknowledge the reality of time delay and irreversibility of capital investments, this condition is highly restrictive and evidently not applicable. On the other hand, historical records of job creations or vacancies show clearly the underlying sluggishness of the start ups in response to new opportunities. This trade off between the model transparency and poor prediction power ( at least in terms of cyclical functions) is not uncommon among calibrated models of the labor market based upon costly search. See, for example, Fujita and Ramey (2007) for their simulations results and the better fit obtained by introducing sunk cost for job creations. For these reasons, the model analysis necessarily fail to keep track of cyclical fluctuations in accessions and separations as we observed during the lost decade.
} 
each parameter.

Table 2 around here

- The one period of the model corresponds to a quarter of a year.

- The annual discount rate is set at $2 \%$, roughly the long run growth rate of the Japanese economy: $r=0.005$

- Assuming the average work career to last 40 years, we set the quarterly retirement probability at $d=0.0063$

- $q^{s}$, per period output for a type $s$ job in the state $g$, is used as the benchmark and we set $q^{s}=1$

- $q^{c}$, the output for a type $c$ in the state $g$ is set at 1.5. This ratio gives rise to roughly 1.5 to 1 in the average wage rate between type $c$ type $s$ workers, which is broadly in line with the differential in wage rate between temporary and regular workers after controlling for the work hours.

- Matching function. We assume that it is a simple Cobb Douglas type.

$$
M=A V^{\eta} U^{1-\eta}
$$

with the coefficient for vacancy, $\eta=0.3$. This specification approximate the coefficient estimates in Kano and Ohta (2005) and Kambayashi and Ueno (2006).

- We use the results from Ito and Lechevalier (2008) for the across firm distribution of labor productivity of full time jobs. Specifically, we set $\theta=0.88$ so that the $\log$ productivity differential between upper $25 \%$ and lower $25 \%$ corresponds to their results.

- We have almost no information directly relevant to this parameter for Japan, but Koike (2005) asserts the firm specific components of human capital is at most $10-20 \%$. Thus we set $\epsilon=0.15$.

- Distribution of the (first job) training cost. We assume $F(\cdot)$ to be a normal distribution with mean $\mu_{z}$ and standard deviation, $\sigma_{z}$, truncated at $x=0$ and re-normalized density such that the probability sums up to unity.

- We set $\mu_{z}=9$. This corresponds to 1.5 years' worth of output for a type $c$ job in the state $g$. Ariga et al. (2006) reports average On the Job Training is 82.5 hours per year among the surveyed sample firms in Manufacturing, which corresponds to $4-5 \%$ of annual work hours, which in turn corresponds to 2 years of 40 year work life. Ariga et al. (2006) also have been conducting by annual surveys at two auto assembly plants and they also find the average monthly training hours around 8-10 hours per month among assembly line employees. This suggests annual training hours around $80-100$. This translates into $5 \%$ of total work hours.

- We set $\rho=0.006$ so that the average duration of "good" state is 40 years.

The remaining seven parameters $\left[\sigma_{z}, \delta_{c}, \delta_{s}, p_{c}, p_{s}, m, A\right]$ are chosen to match the following targets taken from the data 
- Aggregate labor market tightness (vacancy-unemployment) rate at 1.

- The share of temporary and part time workers (type $s$ jobs) among the male was $8.5 \%$ in 1991.

- The average job finding rate (monthly) is around $16 \%$ as in Kuroda(2003).

- 10-year job retention rate for type $c$ jobs is set to .60 , which is the average for age 25-44 for the period 1982-1992 in Kato and Kambayashi (this volume). This corresponds to roughly 20 years as the average duration of type $c$ jobs.

- We target the average duration of type $s$ jobs at 5 years.

- According to the Survey on Employment Trends, roughly $60 \%$ of total job accessions involve industry changes. We use this as the share of the worker mobility from $d$ to $g$ sector in total separations.

- We use the log earnings ratio between college and high school graduates as the benchmark for the differential between upper $25 \%$ and lower $25 \%$ of the discounted life time earnings. The data for 1980-1990 is stable around .2-.25. We set the target at .2 to incorporate the discounting in computing the life time earnings in our model.

\subsubsection{Steady States of the model under base parameterization and macro technology shocks}

We configured parameters in order for the steady state equilibrium of the model to mimic closely the average values of the target variables around 1990. The results are shown in the first column of Table 3 . In the second column, we show the steady state values when we lower the value of $\theta$ from .88 to .84 . Similarly, the third column is for the case wherein $\rho$ is increased from .006 to .012 . Finally, the last column show the steady state when two changes are combined. We calibrated these two changes so that the the new steady state in the last column corresponds to the post bubble steady state.

\section{Table 3 around here}

The steady state values of the variables listed in the first column of Table 3 meets the targets we outlined above: the share of type $s$ employment is $8.4 \%$, corresponding to the target figure, $8.5 \%$, shown above; the mobility across industries comprises $60 \%$ of the total job changes; and, the vacancy size matches total unemployment rate. Job finding rate is also close to the target. The unemployment rate at the bench mark is $3.1 \%$.

About $80 \%$ of employment is at type $c$ jobs which are yet to be hit by the technology shocks, whereas roughly $20 \%$ have type $c$ jobs which are already in the depressed state. We set exogenous separation rate of type s at $15 \%$ per year, and the total annual turnover rate for type $\mathrm{s}$ is $39.4 \%$ (thus separation rate is $19.7 \%$ ) compared to $9.9(4.9 \%)$ for the type c jobs. Thus the endogenous separations account for $2.5 \%$ and $1.2 \%$, respectively, of the separations at type $s$ and type $c$ sectors. This of course reflects the equilibrium effect of training investment. The share of aggregate training cost is $6.2 \%$ of gross output, which is probably over-estimate and this may account for some of the extremely sluggish response in some of the state variables, as we will show below.

The long run effects by two types of macro technology shocks replicate qualitative characteristics we verbally explained in section 3.3. In terms of quantitative effects, 
we lack any empirical counterparts to evaluate. The steady state unemployment after two shocks is $4.5 \%$, which is roughly comparable to the average, $4.7 \%$ for $2002-2007$, the full length of the latest business cycle.

Compared to the modest impact on gross output by either type of shocks, changes in employment shares are larger. Even though the impact on gross output is negligible, the decline in $\theta$ generates $2.2 \%$ increase in type $s$ job, $8.2 \%$ increase in the share of type $c$ jobs in $g$ sector, and $10.4 \%$ decrease in the share of type $c$ jobs in the depressed sector. In the case of an increase in $\rho, 1 \%$ decline in GDP is matched by .7\% increase in the share of type $s$ job, $5.5 \%$ decrease in the share of type $c$ in $g$, and $4.9 \%$ share increase of type $c$ jobs in $d$. If we consider these ratios to be too large to be credible, an economy with lower training cost will show even more larger response ratios of these shares relative to changes in GDP. The implication is that the alarming increase in type $s$ jobs [or in terms of data, steady increase in temporary or part time jobs] may not be so serious in terms of the accompanying loss in output.

The impact on the steady state unemployment is modest compared to these changes: $.5 \%$ increase in $\theta$ or $\rho$, and about $1.4 \%$ when two shocks are combined. GDP declines by $5.1 \%$ with the combined shock so that the ratio of GDP change to the change in unemployment rate is around 3.6. Setting aside the exact number, the low sensitivity of unemployment to GDP change in Japan is a well known feature.

\subsection{Dynamics}

Figures 9-12 around here

We traced the impact of two types of shock over time. We show two results. Figure 9-12 show the dynamic paths of major variables after shocks. In Table 4 we tabulate the time needed for each of major variables to absorb the long run impacts. This is measured in terms of time (in quarters of a year) needed to move half way $(50 \%)$ of the difference between the two steady states, and the time needed for $75 \%$ benchmark. We notice that the dynamics differ somewhat between the two shocks. The transition to the new steady state is relatively fast in the case of $\theta$ shock, which is exactly what we anticipated in section 3.3. In the case of the employment composition between $g$ sector and $d$ sector, the transition from the benchmark steady state to the one with the shock is $75 \%$ complete within 2 years. The only exception is the slow adjustment in the share of type $s$ relative to the combined share of type $c$. It takes 27 years to reach $50 \%$ benchmark, and 50 years to reach $75 \%{ }^{27}$. This is also exactly what we would have expected: the share moves roughly in line with the speed of retirement and entry.

\section{Table 4 around here}

The shock in $\rho$ generates longer adjustment process. Unemployment rate reaches $75 \%$ benchmark only after 24 years. As expected, the adjustment in the share of type $s$ takes longer than in the $\theta$ shock. The difference in the adjustment speed is smaller compared to other variables: 29 years to reach $50 \%$, and 56 years to reach $75 \%$. Again we note that the relatively smaller difference is attributable to the fact that the pace of entry and exit from the labor market determines the base speed of adjustment. With the risk of over simplification, the sluggishness of the $s$ sector

\footnotetext{
${ }^{27}$ You may know already why, but we note that the large numbers shown for the transition time for the share of type $s$ employment is due to the simplifying assumption: i.e., workers are assumed ageless and face a constant probability of retirement. But, remember, the counterpart, the rate of new entry is not very far from the reality.
} 
response is akin to the impact of a change in education attainment on the average education of labor force. By the same token, a policy (say, a subsidy for training) intended to reversal the trend must also takes an excruciatingly long time to generate visible impact.

\subsection{Evaluating government policy}

Table 5 shows the long run impacts of three types of government policy. In the extreme left column, we show the benchmark steady state that corresponds to the steady state shown in the last column of Table 3. Namely, each policy is introduced to the steady state of the economy after the two shocks.

\section{Table 5 around here}

In the second column, we show the steady state associated with a program that subsidizes the rental cost for type $c$ jobs in $d$-sector. In the third column, we show the impact of legal restrictions on firing which we represent by wasteful costs incurred among workers when they leave $d$ sector employment to search for a job in $g$ sector. In the last two columns, we show the impact of a subsidy to training. In the first case, the subsidy is given to all the unemployed workers when he receives training for the first time. In the last column, the subsidy is provided for re-training when workers relocate themselves from type $d$ to type $g$ sector. We set the magnitude of each program in such a way that the expenditure (which we presume to be financed by lump sum tax) is equal to .2\% of GDP, which translates to roughly 1 trillion yen per year in the current Japanese economy. Note that the impacts are computed under the assumption that the program is carried out with the same magnitude forever. Except for the last column, each program has more or less the same impact on long run unemployment rate: about .1\% decline.

The program that subsidizes rental cost of job slot in $d$ sector corresponds closely to various government programs to assist the structurally depressed industries. Subsidies on interest payments are the most common. Our experiment reduces rental cost of type $c$ jobs in $d$ sector by $2.9 \%$. As a result, the share of $d$-sector job increases by $2.6 \%$, most of which is offset by $1.8 \%$ decline in $g$-sector job. A good news is that the overall profitability of type $c$ jobs increases. Hence the share of type $s$ jobs decline by $.8 \%$. The decline in the share of type $s$ jobs thus reduces the share of type $s$ vacancies. Not surprisingly, the labor mobility is somewhat $(.9 \%)$ reduced by such a policy as the policy help survival of jobs in $d$ sector. As expected, policies to assist structually depressed sectors reduce labor mobility and shift the labor allocation away from the healthy and higher productivity sector.

During the lost decade, forbearance and ever-greening of the bank lending to troubled firms allowed the low productivity jobs to survive. Our simulation demonstrates that the negative impacts on labor mobility and productivity were substantial. If we use $p_{c}=.42$, which corresponds to capital stock value at 21 using the $2 \%$ annual discount rate, the corresponding capital output ratio is $3.5\left(q^{c}=6\right)$. According to Caballelo, Hoshi and Kashyap (2008), roughly 15\% (asset weighted) firms received subsidized loans and they estimate $15-20 \%$ of all the firms were "zombies" in late 1990 s to early 2000s. If we use a conservative estimate of $50 \%$ of the total capital (around 1,000 trillion) financed by debt and interest rate at 5\%, the total interest rate payment is about 25 trillion. Thus if the banks forego $20 \%$ of interest payment, that corresponds to 5 trillion yen, roughly 5 times the magnitude of the capital subsidy program explained above. When we estimate the impact of injecting $1 \%$ of output on capital subsidy, our model predicts $11.9 \%$ increase in the employment at 
depressed sectors. Thus, our simulation result is broadly consistent with the estimate of zombie firms by Caballelo, Hoshi and Kashyap (2008).

In the second experiment, we considered the impact of penalizing separations. We gauge the total size of firing cost imposed to $.2 \%$ of GDP. This firing cost is considered social wastes. The firing cost reduces the mobility of the most mobile workers. Thus the share of type $d$ sector increases by $3.4 \%$, which is completely offset by the decline in employment at type $g$ sector. As a result overall mobility declines. The only good news is that the suppressed separations reduce the unemployment. Many labor economists argued that protecting the job by penalizing separations reduce not only the labor mobility, but discourage job creations. Although our results do show that firing cost reduce the labor mobility, the effect on vacancy creation is almost nil (vacancy-unemployment rate is essentially unchanged).

The third experiment is the impact of subsidy for training to the unemployed workers without previous training. The $.2 \%$ of GDP outlay in this experiment corresponds to a $4.5 \%$ proportional reduction of the first time training cost, $z$. Thus a simple way to visualize the experiment is to replace $z$ by $.955 z$ for all those who receive training for the first time. Evaluated at $\mu_{z}=9$, the subsidy is about $10 \%$ of annual output. Using $2 / 3$ as ratio of the wage compensation to the output, subsidy corresponds to $15 \%$ of annual wage. As a result, the share of type $c$ employment increases by $1.9 \%$, out of which $1.1 \%$ is due to the increase in type $c$ jobs in $d$ sector, compared to $.8 \%$ in $g$ sector. The reason is that the subsidy matters more to the workers closer to the threshold between type $c$ and type $s$. Those are the workers with highest training cost among those in type $c$ jobs. Consequently, the impact eventually translates into the concentrated increase in the depressed sector jobs. This point can be confirmed by comparing the impact on thresholds.

If the training subsidy is provided to the workers relocated from type $d$ to type $g$ sector, the subsidy amounts to $9 \%$ of the re-training cost of these workers. The net impact is $2.6 \%$ increase in type $g$ sector employment and the roughly offsetting decline in type $d$ employment. Unlike all other four policy experiments, this re-training program increases the overall labor mobility. Just by coincidence, this impact on type $d$ employment is almost exactly the same in size but opposite of the capital subsidy program. In our model, combination of two programs, capital subsidy and re-training programs cancel out each other, leaving only the effects on type $s$ employment as the only visible impact. Still, both types of policies are popular and often implemented in the past stimulus policy packages in Japan.

\subsection{Impacts on individual workers}

Figure 13 around here

Given the varied endogenous response to shocks, the impact of shocks and policy on workers can differ depending upon the timing and the training cost. Figure 13 shows the impact of the two combined shocks on $\theta$ and $\rho$ on the life time welfare (expected discounted value of net income stream) for untrained (and thus unemployed) workers. As expected, the impact varies widely across workers with different training cost. By far the hardest hit are workers with the highest training cost among those qualified for type $c$ jobs: the maximum impact is more than $8 \%$ of the life time welfare. On the other hand, those who are in type s jobs are least affected as their welfare reduction is less than $2 \%$. As far as the choice between type $c$ and type $s$ jobs reflect only the choice over training investment, and, as far as the individual net benefit from training investment is competitively priced in the labor market, the impact of these shocks are small for those who do not choose to invest in training. Although some of the untrained workers switch from type $c$ jobs to type $s$ jobs after the shock, the 
impact of the shock on these workers are also small. The severity of the technology shocks thus differ sharply from the popular perception: it is those who continue to search for type $c$ jobs who are the hardest hit, not those who apply for type $s$ jobs ${ }^{28}$.

\section{Figures 14-17 around here}

In Figures 14-17, we show the impact of policy experiments shown earlier in Table 5. In the case of capital subsidy to the type $d$ sector jobs, the gain is the largest for those in the range of training cost in which they actually take up jobs in type $d$ sector. Their net life time income increases by about .5\%. The cost is born by the rest of the workers in terms of the decline in the life time net income. In the case of firing cost, the burden is concentrated in those with the lowest training cost as these workers are most mobile and have to incur the firing cost every time they move out of the job hit by the technology shock. Subsidy for the untrained workers benefit most to those with highest training cost among those qualified for type c jobs. The workers with higher training cost and apply for type s jobs, suffer the most. Finally, the subsidy for the re-training benefits most those who bear relatively large training cost yet mobile enough to move out of jobs whenever it is hit by the productivity shock. Again, type $s$ workers never benefit from the re-training subsidy as they do not receive any training. It is interesting to see that all these policies tend to benefit most those workers in the middle range of training cost while those who are in type $s$ jobs are those with the most mobile workers either receive little benefit or actually hurt by these policies. Those with smallest training cost, hence the most mobile, suffer from subsidies to training as the proportional subsidy is small relative to the tax burden. They never keep a job in d sector so capital subsidy to these jobs do not benefit them. They suffer most from legal restriction on firing. By the similar token, none of the policies have any direct impact on workers in type s jobs and they only bear the tax burden.

All of these policies shown in Table 5 have been implemented in the past in Japan. Essentially, all these policies cater to the benefit of those majority of workers who are in type $c$ sector, but not very mobile, i.e., those core employees in the Japanese employment system characterized by the heavy initial training and job security. These policies are at least partially responsible for the sluggish employment adjustment in Japan.

\subsection{An economy without firm specific training ${ }^{29}$}

If the combination of the technology shock and heavy relation specific investment is responsible for the stagnant economy and low labor mobility, one natural question we can pose is: what if the same shock hit an economy wherein skills are more easily transferable. Our model has two key parameters, $\epsilon$ and $m$ that govern the degree of specificity of skills. If $\epsilon=0$, skills are perfect substitute across firms within the same industry (industry), whereas $m=0$ implies that no additional cost is involved by moving across industries. In Table 6, we consider two hypothetical economies and compare the impact of shocks vis-a-vis our benchmark economy. In case 1, we set $\epsilon=0$ and leave $m$ unchanged at 0.42 , whereas in case 2 , we set $m=0.21$, a half of the benchmark.

\section{Table 6 around here}

\footnotetext{
${ }^{28}$ Needless to say, our model abstracts from dimensions other than the training cost in which two types of jobs differ in reality, and our results should be interpreted with due cautions.

${ }^{29}$ We thank David Weinstein for suggesting these simulations.
} 
In both cases, we find technology shocks are absorbed more by enhanced worker mobility. For example, in our benchmark economy, the combined shocks reduce the employment in $g$ sector by $9 \%$, whereas in both case 1 and case 2 , the net reductions are significantly smaller. In case 2 , the impact is roughly a half $(4.6 \%)$ of the benchmark economy. The other side of the decline in $g$ sector is a steep rise in type $s(7.3 \%)$ and $d(1.8 \%)$ jobs in the benchmark economy. In contrast, both in case 1 or case 2 , the jobs in depressed sector declines as a result of increased labor mobility. Increase in type $s$ jobs are also somewhat smaller.

The discounted value of income stream for the untrained worker, the relevant welfare measure, declines by $5 \%$ in the benchmark case, but the impacts are smaller in the two cases. The only exception is that the unemployment rate increases roughly equal or by somewhat larger amounts in alternative economies. Since the unemployment rates are .2-.4\% higher before the shock in comparison with the benchmark economy, the steady state unemployment rates after the macro shock are somewhat higher in both cases. The annual worker turnover rate responds more to the shocks and the impact of shocks on welfare and output are better mitigated, if the specificity of trainings is reduced.

\section{Conclusion}

We have shown that the sluggish response of the labor market to a shock can be understood as the equilibrium outcome in an economy with search friction and partially relation specific investment in training. That, by itself, is not surprising or new ${ }^{30}$. Our contribution is to show that such an economy also have other features which we find in the Japanese labor market. We have shown that a relatively modest change in a parameter governing the nature of productivity shock is enough to cause a long but steady increase in the share of jobs that do not require training. This impact causes history dependence because of the sunk cost nature of training. The same cohort of workers with the same innate ability can have a totally different job history. The effect will last as long as this induced heterogeneity is eventually washed away by the retirement of the cohort from the labor market. We also have shown that a modest size of negative macro technology shock is enough to explain a sizable (say, 1.5\%) increase in the long run unemployment rate, without much visible impact on the unemployment-vacancy ratio or the turnover ratio. I.e., Beveridge curve shifts out. When we allow two technology parameters to change, the combined outcome shows all of these changes, yet the steady state values of employment turnovers differ little from the baseline. The big jump occurs, however, in the share of employment in type $s$ jobs. Even after the deepening of the productivity shock, the new steady state has roughly the same share of workers clinging to the jobs with lower productivity as the effect of higher probability of permanent shock almost cancels out the first effect. A large share of those will search and work in those jobs until retirement. The end result is that the shrinking primary sector jobs in the $g$ sector. These results are consistent with the changes in the Japanese labor marker in the last two decades. We also have shown that an economy with smaller cost of re-training would respond to the shock by increased labor mobility, thus mitigating the impact of the shock. Although the unemployment rate will be higher, and more responsive to the technology shocks, the impacts on welfare and output are mitigated. The results are in line with a conventional wisdom on the difference between the Japanese and the U.S. labor markets.

On the other hand, some of the findings in our analysis runs counter to the

${ }^{30}$ See for an early contribution by Fukao and Otaki (1993). 
conventional wisdom, or, at least to the popular perception. In terms of the loss in life time earnings, the impact of the shock is the largest among a group of type $c$, not type $s$ workers: they are the workers with the highest training cost among those who continue to work in type $c$ jobs. Among type $s$ workers, these technology shocks impose only limited cost as they do not invest in training at all so that increased frequency or magnitude of technology shocks only results in marginally higher job separation rates.

Policy simulations show that the popular government policies implemented in the past indeed have some impacts in retaining the core of the Japanese employment system: they cater to the interest of the workers who invest heavily in the early stage of the career and tend to retain the job for long time. The effectiveness comes at the cost, though. Those who are the most mobile tend to benefit little and bears the tax burden. More importantly, such a policy can easily perpetuate the status quo and only caters to the interest of those who have invested in the past on skills and stand to lose most after major technological changes. To evaluate the precise welfare consequences of these policy, we need careful quantitative analysis of the general equilibrium effects, which is beyond the scope of this paper.

At the onset of another shock waves from the other side of the Pacific, we hear the outcry for the massive government expenditure against what appears to be the severest recession in the entire post war history. Given the likely scale of the policy to be enacted, the long run impact of such a policy package will be substantial and longer lasting. If the track record of the lengthy and costly recovery from the lost decade offers any guidance, it is that the short run macroeconomic policies to restore the macroeconomic imbalance must be compatible with the long run policy targets. 


\section{A Appendix: Formal Description of Market Equilibrium}

\section{A.1 Set up}

As we explained in the main text, we assume the constant population of workers. All the participants in the labor market are risk-neutral and use the common discount rate $r$.

We consider two types of jobs, type $c$ and type $s$. The productivity of both jobs depend on the state of the industry. There is a continuum of the industry and the state of each industry evolves according to the following simple stochastic process. There are two possible states, ' $g$ ' (good) and ' $d$ ' (depressed). The collection of the industries in each state is called sector. Thus $g$-[ $d-]$ sector collects all the $g$ [d-] industries. Each industry in state $g$ turns to the state $d$ with probability $\rho$, representing the permanent productivity shock. In order to prevent all the existing industries becoming $d$, we assume the continuum of the industry expands over time so that there always exists strictly positive mass of the industries in state $g$. Let $q^{c}\left[q^{s}\right]$ denote the output per unit of time of a type $c[s]$ job in $g$-sector filled by a properly trained worker. As we explained in the main text, each worker is endowed with innate aptitudes for type $c$ jobs and we represent by $z$ the worker continuum in terms of the training cost needed. The value $z$ represents the cost of the first training. We assume that such a cost is payable in once and each training is complete once the cost is incurred. We denote by $F$ the distribution of $z$.

The basic building blocks of the model are the firms' job offers and workers' application strategies. The job offer must stipulate employment and compensation in all payoff relevant contingencies: i.e., required type of the worker, the type of job slot, the industry, and wage schedule which can be contingent on the state of industry. Such a job offer maximizes the profit given the application strategies of each type of unemployed workers. Workers are distinguished by training cost $z$ and the last training she has taken. As we will see shortly, no worker receives training for the first time at a type $c$ job which is already in the state $d$. Still, an unemployed worker could have received training at a job which is currently in $g$-sector, or, in $d$-sector, or, never been trained before. Although a worker can search for a job in any industry, if the job where he received the training is currently in $g$ sector, he has no reason to search in a different industry because all the industries in the $\mathrm{g}$ sectors are identical because of the imposed symmetry of the industries. A worker may move out, however, from the industry where he received training if the industry has moved to the $d$-sector and job productivity is lower. Therefore a sub market in $d$ - sector is populated only by those who received the training in the same industry, whereas sub markets for jobs in $g$ sector can be populated by workers with training in $g$ as well as $d$.

Let $e=g, d$, denote the current state of the industry where he received training and denote by $e=n$ for the untrained. Let $T \equiv\{g, d, n\} \times Z$ denote the set of types of unemployed worker. Although a worker can be trained more than once, what matters is the most recent training ${ }^{31}$. Thus the notation of the type of training refers to the most recent one. Note that the training type of the worker can change over time for two reasons. First the state of the industry where he received training can change. Second, once he is employed, he receives re-training.

The job offer can be identified by the pair of wage schedule $w=\left(w_{g}, w_{d}\right)$ and contract types, wherein $w_{g}\left[w_{d}\right]$ denotes the wage offer contingent upon the industry being in the state $g[d]$. For each cohort of workers with given training cost index

\footnotetext{
${ }^{31}$ As no one choose to go back to the industry now in the state $d$, all the past trainings before the last must have been in the industries which are now all in $d$ sector.
} 
$z$, the following types of contract types are possible. Let us start with contract types in type $c$ jobs. First, the offer can be contingent upon the state of the industry. By contingent contract, we mean that the employment is terminated once the industry is hit by the shock. For simplicity, we also assume that in this type of contract the job slot itself is self-destroyed when hit by the productivity shock ${ }^{32}$. Since we only consider a permanent shock, the state $d$ is permanent. A job in $g$ sector can also offer an unconditional employment contract, except for the exogenous separations. Namely, an unconditional contract guarantees employment after the shock (but a worker can of course walk away any time they want). Since the state $d$ is permanent, all the employment offer is unconditional guarantee. Hence we need to consider contingent employment offer only for jobs currently in $g$-sector. By the same token, non-trivial contingent wage schedule applies only to one type, i.e., the one that promises unconditional employment.

For untrained workers, no offers from jobs in $d$ sector can compete with those in $g$ sector because, for the untrained workers, the only difference between the two is lower productivity in $d$. Thus all the untrained workers will choose industries in $g$ sector. We impose symmetry on the selection among the totally homogenous industries in the $\mathrm{g}$ sector so that each industry is populated with the same density of the untrained workers.

We now consider contract types for type $s$ jobs. It is easy to see that there can be only two types of contracts, conditional and unconditional employment in $g$-sector because unfilled job slots are immediately discarded as soon as the industry is hit by the shock. This is the case because type $s$ jobs do not need any training. Thus there is no advantage of retaining the vacancies in $d$-sector. Consequently there is no active job slot that will post an offer. Again we assume each industry in $g$ sector has the same size of the workers searching for a job ${ }^{33}$.

Consequently we need to consider the following five types of contracts: unconditional type $c$ in the $g$-sector $(\bar{g})$, conditional type $c$ in the $g$-sector $(\hat{g})$, (unconditional) type $c$ in the $d$-sector $(d)$, unconditional type $s(\bar{s})$, and conditional type $s(\hat{s})$. While unconditional employment contract is never terminated by the employer, conditional employment contract is terminated when the sector is hit by a permanent productivity shock without any compensations.

Since the firm can make an offer contingent on the type of worker, we can define the type contingent employment contract by the pair $\{\mathcal{C}, \mathcal{W}\}$, where $\mathcal{C}: T \rightarrow C$ and $\mathcal{W}: T \rightarrow \mathbb{R}_{+}^{2}$ are mapping from worker type to offer types and wage schedule, respectively. $C \equiv\{\bar{g}, \hat{g}, d, \bar{s}, \hat{s}\}$ is the set of type of contract. Thus each sub-market is fully specified by the job offer. In each sub market, all the job offers are of the same type, and all the workers are of the same type. Denote by $x$ the ratio of job searchers to the vacancy, which we call queue length. Then the probability that a vacancy receives at least one application is given by $\psi(x)$, which is increasing and strictly concave in $x$.

Now that the description of each sub market is complete, an allocation of the economy can be fully specified by a tuple $\{\mathcal{C}, \mathcal{W}, x\}$ where $x: T \rightarrow \mathbb{R}_{+}$is the queue length in each sub market. Given the allocation $\{\mathcal{C}, \mathcal{W}, x\}$, we can compute the expected present value of profit stream for a job slot and the corresponding value of

\footnotetext{
${ }^{32}$ This simplifying assumption is used only to avoid further crowding of notations. As we impose the zero profit condition, all the existing vacancy at equilibrium will have zero value anyway.

${ }^{33}$ Notice that because of the free access to the underlying technology, single industry can accommodate any size of job vacancies and workers. Although uneven distribution across industries are immaterial as far as they remain in $g$ sector, the impact of the technology shock on the aggregate labor market obviously will depend upon the size of the industry hit by the shock. We avoid this unnecessary complications by imposing symmetry.
} 
the expected income stream for a worker. Let $V_{c}(w, x)$ be such value for a vacancy that post the offer $(c, w)$, where $c \in C$ is type of offer. Then we have

$$
r V_{c}(w, x)=-p(c)+\psi(x)\left[J_{c}(w)-V_{c}(w, x)\right] .
$$

where $p(c)=p_{c}$ if $c=\bar{g}, \hat{g}, d$ and $p(c)=p_{s}$ otherwise. Viz, the cost of maintaining a job slot is $p_{c}\left[p_{s}\right]$ for type $c[s]$ jobs. The value of filled job depends upon the state contingent wage schedule $w=\left(w_{g}, w_{d}\right)$ and the type of contract $c$ and given by

$$
\begin{aligned}
& r J_{d}(w)=\theta q^{c}-w_{d}-p_{c}-\left(\delta_{c}+d\right) J_{d}(w), \\
& r J_{\bar{g}}(w)=q^{c}-w_{g}-p_{c}-\left(\delta_{c}+d\right) J_{\bar{g}}(w)+\rho\left[J_{d}(w)-J_{\bar{g}}(w)\right], \\
& r J_{\hat{g}}(w)=q^{c}-w_{g}-p_{c}-\left(\delta_{c}+d+\rho\right) J_{\hat{g}}(w), \\
& r J_{\bar{s}}(w)=q^{s}-w_{g}-p_{s}-\left(\delta_{s}+d\right) J_{\bar{s}}(w)+\rho\left[J_{d}^{s}(w)-J_{\bar{s}}(w)\right], \\
& r J_{\hat{s}}(w)=q^{s}-w_{g}-p_{s}-\left(\delta_{s}+d+\rho\right) J_{\hat{s}}(w),
\end{aligned}
$$

where $J_{d}^{s}(w)$ is given by

$$
r J_{d}^{s}(w)=\theta q^{s}-w_{d}-p_{s}-\left(\delta_{s}+d\right) J_{d}^{s}(w)
$$

In words, the first is the value function for an active contract in state $d$. The first three terms sum up to the net flow profit, and the last term corresponds to the capital loss upon worker retirement or exogenous separations. The second and the third are the value function of type $c$ jobs for contracts in $g$ state. The last two equations are for type $s$ jobs in the state $g$. Note that a permanent shock occurs only to jobs in $g$ industries. The unconditional employment contract continues even after the sector is hit by permanent shock but it incurs the capital loss due to the change of state. On the other hand, the conditional employment contract terminates and the job slot is destroyed if the sector is hit by permanent shock. Thus the value of job turns to be zero.

Next, we consider the value of unemployed worker given the allocation and the equilibrium value of each type of unemployed worker. The rational unemployed workers choose their application strategies taking their future change of training into account. Here, we incorporate the equilibrium value into the value function instead of considering the future decision directly. Let $U_{c}\left(t, w, x, U^{*}\right)$ be the value of type $t$ unemployed worker given the wage schedule, contract type, queue length, and equilibrium value of unemployed worker, which we denote by $U^{*}$. In this formulation, we treat as given the value of different types of unemployed workers, even though in the future he may become one of those types. We thus focus on the optimal choice of the current application strategy. We have

$$
\begin{aligned}
r U_{c}\left(t, w, x, U^{*}\right)= & \phi(x)\left[E_{c}\left(z, w, U^{*}\right)-U_{c}\left(t, w, x, U^{*}\right)-\kappa(c, t)\right] \\
& -d U_{c}\left(t, w, x, U^{*}\right)+I(e) \rho\left[U^{*}(d, z)-U_{c}\left(t, w, x, U^{*}\right)\right],
\end{aligned}
$$

where $\phi(x) \equiv \frac{\psi(x)}{x}$ is the probability of being matched for a worker, and $I(\cdot)$ is indicator function that takes value one if $e=g$ and zero otherwise. The last term in the square bracket is the capital loss associated with productivity shock which is applicable only for a worker trained in $g$-sector. 
The training cost $\kappa(c, t)$ is given by ${ }^{34}$

$$
\kappa(c, t)= \begin{cases}0 & \text { if } c=\bar{s}, \hat{s} \\ z & \text { if } e=n \text { and } c \neq \bar{s}, \hat{s} \\ \epsilon z & \text { if }(e, c)=(d, d),(g, \bar{g}),(g, \hat{g}) \\ (\epsilon+m) z & \text { otherwise }\end{cases}
$$

In words, the first case applies to type $s$ jobs irrespective of contract types as no training is required for this type of job. If a worker is never trained and he applies for a type $c$ job, full training cost must be incurred, irrespective of the contract type. In the third line, we show the following: a worker have to pay $\epsilon z$ if he decides to search and apply for a type $c$ job in the same industry where he received the last training. Finally the same worker has to incur $(\epsilon+m) z$ if he decides to move out of the current industry and being matched to a type c job in the $g$-sector.

The value of employed worker depends on the training cost index $z$ and wage. They are represented by the following value functions for employment.

$$
\begin{aligned}
r E_{d}\left(z, w, U^{*}\right)= & w_{d}-\delta_{c}\left[E_{d}\left(z, w, U^{*}\right)-U^{*}(d, z)\right]-d E_{d}\left(z, w, U^{*}\right), \\
r E_{\bar{g}}\left(z, w, U^{*}\right)= & w_{g}-\delta_{c}\left[E_{\bar{g}}\left(z, w, U^{*}\right)-U^{*}(g, z)\right]-d E_{\bar{g}}\left(z, w, U^{*}\right) \\
& +\rho\left[E_{d}\left(z, w, U^{*}\right)-E_{\bar{g}}\left(z, w, U^{*}\right)\right], \\
r E_{\hat{g}}\left(z, w, U^{*}\right)= & w_{g}-\delta_{c}\left[E_{\hat{g}}\left(z, w, U^{*}\right)-U^{*}(g, z)\right]-d E_{\hat{g}}\left(z, w, U^{*}\right) \\
& +\rho\left[U^{*}(d, z)-E_{\hat{g}}\left(z, w, U^{*}\right)\right], \\
r E_{\bar{s}}\left(z, w, U^{*}\right)= & w_{g}-\delta_{s}\left[E_{\bar{s}}\left(z, w, U^{*}\right)-U^{*}(n, z)\right]-d E_{\bar{s}}\left(z, w, U^{*}\right) \\
& +\rho\left[E_{d}^{s}\left(z, w, U^{*}\right)-E_{\bar{s}}\left(z, w, U^{*}\right)\right], \\
r E_{\hat{s}}\left(z, w, U^{*}\right)= & w_{g}-\delta_{s}\left[E_{\hat{s}}\left(z, w, U^{*}\right)-U^{*}(n, z)\right]-d E_{\hat{s}}\left(z, w, U^{*}\right) \\
& +\rho\left[U^{*}(n, z)-E_{\hat{s}}\left(z, w, U^{*}\right)\right],
\end{aligned}
$$

where

$$
r E_{d}^{s}\left(z, w, U^{*}\right)=w_{d}-\delta_{s}\left[E_{d}^{s}\left(z, w, U^{*}\right)-U^{*}(n, z)\right]-d E_{d}^{s}\left(z, w, U^{*}\right)
$$

This completes the specifications of all the value functions for potentially active contract and job types.

\section{A.2 Market equilibrium}

We now complete the specification of the model by imposing the zero profit condition for all the active vacancies. Note by the complementary slackness, expected net value of inactive vacancies must be non-positive.

We are ready to define the market equilibrium.

Definition 1. The market equilibrium is defined by the set $\left\{\mathcal{C}^{*}, \mathcal{W}^{*}, x^{*}, U^{*}, V^{*}\right\}$ that satisfies the following conditions.

1. For any type $t \in T$, firms post vacancies so as to maximize their values under the constraint that the offer must guarantee the equilibrium value $U^{*}(t)$,

\footnotetext{
${ }^{34}$ Who actually pays the training cost is immaterial. If you so wish, we could add another dimension in the contract type, depending upon who pays the training cost. Since training cost is independent from the state (although its consequence does depend upon the state in the future), contracts stipulations on who pays (how much) for the training is redundant. To put it differently, if a firm offers a contract in which they pay the training cost, the equilibrium value of the offer will be the same as the current one in that wage schedule will be adjusted accordingly. Needless to say, who pays the training cost does matter at least potentially, if we allow incompleteness of the contract. See section 5 of this appendix below.
} 
i.e., given that queue lengths are determined so as to be consistent with the equilibrium value of unemployment $U^{*}(t)$. Therefore, we have

$$
\left(\mathcal{C}^{*}(t), \mathcal{W}^{*}(t), x^{*}(t)\right) \in \arg \max _{c, w, x} V_{c}\left(w, x^{*}\right) \equiv V^{*}(t)
$$

subject to

$$
U^{*}(t) \geq U_{c}\left(t, w, x, U^{*}\right)
$$

and $x \geq 0$ with complementary slackness, where $U^{*}$ solves

$$
\forall t \in T \quad U^{*}(t)=U_{\mathcal{C}^{*}(t)}\left(t, \mathcal{W}^{*}(t), x^{*}(t), U^{*}\right)
$$

2. By the free entry condition, the maximized value of active vacancies, $V^{*}(t)$, must be equal to zero.

In equilibrium, a job slot computes the value of deviation based on the belief that the queue length that corresponds to alternative job offer should be adjusted so as to guarantee to the unemployed workers the market determined present value of the expected income stream. In order to obtain the market equilibrium, we can solve the problem,above, or, equivalently, we can solve the dual. That is, we maximize the value of the unemployed worker conditional under the zero profit condition.

$$
\begin{aligned}
U^{*}(t)=\max _{c, w, x} & U_{c}\left(t, w, x, U^{*}\right) \\
& \text { s.t. } \quad V_{c}(w, x)=0
\end{aligned}
$$

Before we move on to analyze the market equilibrium defined above, we offer verbal explanations why the market equilibrium defined above coincides with that of a social planner. Given the full array of contractual arrangements, the market equilibrium defined above evidently solves the resource allocation problem for a social planner endowed with the same search technology, technology evolutions underlying productivity shocks to job slots. In order to see through the logic behind, let us assume for the time being that both job slots and workers are identical among themselves and assume away also the productivity shocks, etc. None of these additional factors matters for this explanation. Under this simplified setting, an individual offer is simple a wage rate at matched worker receives. The competitive search equilibrium is such that the individual agents take the value of the unemployed worker, $N^{*}$ given. From the viewpoint of each job slot, its own wage offer must satisfy the constraint

$$
\phi(x) M(w)=N^{*}
$$

Namely the product of the probability that an application results in an offer , $\phi(x)$, and the value of the offer, $M(w)$,should be equal to the market determined $N^{*}$. Since

$$
\phi(x) \equiv \frac{\psi(x)}{x}
$$

we have

$$
N^{*}=\frac{\psi(x) M(w)}{x},
$$

namely, this is the trade off between more attractive (hence higher wage) offer and the probability that a job is filled. Since the offer competition guarantees that $N^{*}$ 
is the shadow price of the unemployed worker, the profit maximization condition ensures that the optimal choice of queue length, $x$, coincides that of a social planner. 35 .

We now solve the problem (A6) in two steps. First, we calculate the value of unemployment worker given the type of employment contract, and then compare these contracts. To be specific, we derive the following value at first

$$
\begin{array}{r}
U_{c}\left(t, U^{*}\right) \equiv \max _{w, x} U_{c}\left(t, w, x, U^{*}\right) \\
\text { s.t. } \quad V_{c}(w, x)=0
\end{array}
$$

then solve the functional equations

$$
U^{*}(t)=\max _{c} U_{c}\left(t, U^{*}\right) .
$$

In order to derive market equilibrium, we must look for the optimal employment contract for each type of worker. The following points that we already made are helpful in deriving the desired functional. First, recall that the untrained or those trained in the $g$ sector should apply to the job in the $g$-sector since they have no advantage to work in $d$-sector. In addition, the worker who search for type $s$ jobs should also apply to the job in the $g$-sector. The crucial remaining problem is whether or not to move for those who received training in the industry which now belongs to $d$-sector. To put this question in terms of contract choice, the question is : when the unemployed worker applies to the job in the $g$-sector, should she choose the unconditional employment contract or not?

Next, note also that the trained workers never apply to type $s$ job in the steady state equilibrium. This is evident from the stationarity of the optimal policy: the fact that he received trained in the past implies that it was optimal to apply for a type $c$ job. Then, it should be optimal to do so now, as well. Therefore the third remaining question is which type of untrained worker should apply to type $s$ job.

The following proposition gives the answer to the second. For the last question, we have to wait until section A.4.

Proposition 1. The comparison between the value of unconditional contract and conditional contract can be implemented by the checking the following inequality.

$$
U_{\bar{g}}\left(t, U^{*}\right) \gtrless U_{\hat{g}}\left(t, U^{*}\right) \Leftrightarrow(r+d) U^{*}(d, z) \lessgtr \theta q^{c}-p_{c}
$$

The intuition behind the Proposition 1 is as follows. From (A2) and (A5), the joint surplus that is gained by a match in $d$-sector is given by

$$
E_{d}\left(z, w, U^{*}\right)+J_{d}\left(z, w, U^{*}\right)-U^{*}(d, z)=\frac{\theta q^{c}-p_{j}-(r+d) U^{*}(d, z)}{R_{j}}
$$

Therefore, Proposition 1 says that the unconditional employment contract is preferred to the conditional contract if and only if the joint surplus from declining job is positive. The proposition also implies that the comparison between unconditional contract and conditional contract hinges only upon innate trait $z$, it does not change according to career path of worker. The unemployed worker trained in the [current]

\footnotetext{
${ }^{35}$ See Moen and Rosen (2004) for a more formal proof in a similar model. The formal proofs (omitted) for our case involves straight forward but lengthy derivations of optimal policy for a social planner that solves the corresponding Hamiltonian defined upon the net social output. The solutions of course coincide with those given here for market equilibrium.
} 
$g$-sector always should apply to the type $c$ job in the $g$-sector. Hence the equilibrium value must satisfy

$$
U^{*}(g, z)=\left\{\begin{array}{l}
U_{\bar{g}}\left((g, z), U^{*}\right) \text { if }(r+d) U^{*}(d, z) \leq \theta q^{c}-p_{j} \\
U_{\hat{g}}\left((g, z), U^{*}\right) \text { if }(r+d) U^{*}(d, z)>\theta q^{c}-p_{j}
\end{array}\right.
$$

Therefore, the optimal application of type $(g, z)$ unemployed worker depends on the expected income of type $(d, z)$ unemployed worker. We solve the optimal application problem of type $(d, z)$ worker, which is the most important decision in our model, in the following section.

\section{A.3 The optimal policy for trained workers}

In order to derive the optimal policy of type $(d, z)$ [ those trained in the industry which is currently in $d$-sector] unemployed worker, we consider the case wherein the worker always chooses the same type of contract irrespective of his past choices. The option values that correspond to these strategies can be defined recursively

$$
\begin{array}{r}
\tilde{U}_{c}(t) \equiv U_{c}\left(t, \tilde{U}_{c}\right)=\max _{w, x} U_{c}\left(t, w, x, \tilde{U}_{c}\right) \\
\text { s.t. } \quad V_{c}(w, x)=0
\end{array}
$$

Here we can find the equilibrium value of type $(d, z)$ unemployed worker by comparing these values. If the type $(d, z)$ worker should apply to the job in the $d$-sector, then his re-training (costing $\epsilon z$ ) would not change his training type. Therefore stationarity implies that he should apply to the same type of job in the future as well. On the other hand, by Proposition 1, if it is optimal to move out and search for a new job in $g$ sector, he should choose the same policy in the future even though re-training could change the type of worker. Therefore, in equilibrium, type $(d, z)$ unemployed worker should apply to the same type of contract even after he receives re-training. That is, we have

$$
U^{*}(d, z)=\max _{c \in\{d, \bar{g}, \hat{g}\}} \tilde{U}_{c}(d, z)
$$

We can show that the optimal contract for type $(d, z)$ worker is monotone in $z$.

Lemma 1. Let $x_{c}(t)$ be the queue length that maximizes the present value of the expected income stream of type $t$ unemployed given the type of contract $c$ and the subsequent value $U(t)$. Then the value can be written as the function of queue length,

$$
U_{c}(t, U)=\frac{\Delta\left(x_{c}(t)\right) p(c)+I(e) \rho U(d, z)}{r+d+I(e) \rho}
$$

where $\Delta(x)=\psi^{\prime}(x) /\left(\psi(x)-\psi^{\prime}(x) x\right)$. Moreover, if $U(t)=U_{c}(t, U)$, then we have $x_{c}(g, z) \leq x_{c}(d, z)$ for any $c$ and $z$. That is, type $(g, z)$ worker has larger probability to receive an offer than type $(d, z)$ worker if he seek the same type of job.

Proposition 2. Suppose that type $\left(d, z^{u}\right)$ unemployed worker is indifferent between staying in the $d$-sector and re-entering the g-sector, i.e., $\tilde{U}_{d}\left(d, z^{u}\right)=\tilde{U}_{g}\left(d, z^{u}\right)$, where $\tilde{U}_{g}(d, z)=\max \left\{\tilde{U}_{\bar{g}}(d, z), \tilde{U}_{\hat{g}}(d, z)\right\}$. Then, we have

$$
U^{*}(d, z)=\left\{\begin{array}{lll}
\tilde{U}_{d}(d, z) \text { if } & z \geq z^{u} \\
\tilde{U}_{g}(d, z) \text { if } & z<z^{u}
\end{array}\right.
$$

In addition $U^{*}(d, z)$ is decreasing in $z$. 
Proposition 2 can be stated in words as follows. The difference in $z$ yields the difference in value of unemployed worker which is proportional to the additional training cost in future. Thus the impact of $z$ is smaller if you stay at $d$-sector because re-training cost is proportionally larger if you move out to $g$-sector, i.e., the negative slope of $U$ is steeper if you move out, than at $d$-sector. Hence the intersection at $z^{u}$ of the two value function is unique. Consequently, only the high ability worker $\left(z>z^{u}\right)$ should move out to a new industry in the $g$-sector after the productivity shock, whereas the low ability worker $\left(z<z^{u}\right)$ should stay in the same industry after the shock.

We can also show that the choice between unconditional contract and conditional contract is monotone in $z$ because $U^{*}(d, z)$ is decreasing in $z$. Let define $z^{e}$ by $U^{*}\left(d, z^{e}\right)=\left(\theta q^{c}-p_{c}\right) /(r+d)$. Then those with lowest training cost $\left(z<z^{e}\right)$ should move every time after the shock, i.e., they choose type $\hat{g}$ job if $z^{e}<z^{u}$. (see Figure $5)$

\section{A.4 The optimal policy for untrained workers}

Given the optimal choice of experienced workers, as summarized in the two thresholds, $z^{u}$ and $z^{e}$, we can finally solve the optimal strategies of untrained workers. The untrained workers must incur the same amount of training cost $z$ regardless of the state of sector as long as they apply to type $c$ job, thus they should apply to the job in the $g$-sector if they apply to type $c$ job. The choice between unconditional contract and conditional contract is determined by $z^{e}$ as in the case of type $(g, z)$ worker. That is, we have

$$
U_{g}(n, z) \equiv \max \left\{U_{\bar{g}}(n, z), U_{\hat{g}}(n, z)\right\}=\left\{\begin{array}{l}
U_{\bar{g}}\left((n, z), U^{*}\right) \text { if } z \geq z^{e} \\
U_{\hat{g}}\left((n, z), U^{*}\right) \text { if } z<z^{e}
\end{array}\right.
$$

The last remaining problem is who should apply for a type $s$ job. Since this type of job does not require training, the choice should be unanimous for those who choose type $s$. Let $U_{s}=\max \left\{U_{\bar{s}}, U_{\hat{s}}\right\}$ denote the value of unemployed worker who searches for type $s$ job. If $U_{s}>U_{g}(n, z)$, type $z$ worker should apply to type $s$ job when he enters the labor market. Let $z^{s}$ be the threshold that satisfies $U_{s}=U\left(u, z^{s}\right)$. Since we can show that $U_{g}(n, z)$ is decreasing in $z$, the worker should apply to type $s$ job if $z>z^{s}$.

Suppose that $z^{e}<z^{u}<z^{s}$. Then, we can summarize the optimal strategy of each ability of unemployed worker as follows. First, the most talented workers $\left(z<z^{e}\right)$ always apply to type $c$ job in the $g$-sector and leave the job if the sector is hit by permanent shock. Second, $z \in\left[z^{e}, z^{u}\right)$ workers also apply to the type $c$ job in the $g$-sector but they stay in the $d$-sector as long as they are employed. Third, type $z \in\left[z^{u}, z^{s}\right)$ workers apply to the type $c$ job in the $g$-sector when they enter the labor market and stay in the same sector even though they become unemployed. Finally, the least adaptable $z \geq z^{s}$ worker always apply to the type $s$ job in the $g$-sector.

Now we have made the full circle and the market equilibrium is completely determined except for the evolution of the state variables, which are shown in section A.6. Notice that we have the complete system of equations which jointly determine the equilibrium values of unemployment and employment. See the last section of this appendix for the details of derivations for the optimal queue lengths. These values are independent from the dynamics through which state variables converge to the steady state. 


\section{A.5 Ex Post Optimality and Incomplete Contract}

In the definition of market equilibrium, we assumed that job slots offer two types of contract: contingent and non-contingent employment contracts. The former stipulates that the employment is terminated at the moment of the productivity shock. On the other hand, in unconditional contract, wage is made contingent upon the state. If we deprive of full commitment ability, and assume instead agents are restricted to offer non-contingent wage and employment. In that case, time inconsistency problem may arise: namely, when they post the vacancy, their optimal choice of offer entails unconditional employment at a wage rate which is also unconditional. Ex post, when the job slot filled by a worker is hit by the productivity shock, the job slot may well find it optimal to renege on the promise as the expected return under the depressed state may well be negative.

Now let us return to the contingent wage schedule contract. We show that firms can avoid the time inconsistency problem if the state contingent wage schedule is available. Whether wage schedule is state contingent or not matters only for the case in which a job slot posts an unconditional employment contract. In the proof of Lemma 1, we have shown how the queue length for each type of worker is determined by the optimal (first order) condition, whereas the optimal wage schedule is derived by substituting the queue length into the zero profit conditions.

Since single zero profit condition can pin down only the discounted sum of the state contingent wage, there are (infinitely) many wage schedules that satisfy this condition. That is, the optimal wage schedule of the unconditional employment contract is not unique. The conditions, by which the retention of employment in $d$-sector is made ex post optimal for both sides, are:

$$
\begin{aligned}
\frac{\theta q^{c}-w_{d}-p_{c}}{R_{c}} & \geq 0, \\
\frac{w_{d}+\delta_{c} U^{*}(d, z)}{R_{c}} & \geq U^{*}(d, z) .
\end{aligned}
$$

which are equivalent (respectively to)

$$
\begin{aligned}
J_{d}(w) & \geq 0, \\
E_{d}\left(z, w, U^{*}\right) & \geq U^{*}(d, z) .
\end{aligned}
$$

where $R_{c}=r+d+\delta_{c}$. Therefore, if $w_{d}$ satisfies

$$
(r+d) U^{*}(d, z) \leq w_{d} \leq \theta q_{c}-p_{j},
$$

then the unconditional contract is ex post optimal. We can show that this condition can be satisfied when the joint surplus from the retention of job in $d$-sector is nonpositive. This always holds true if type $\bar{g}$ contract is ex ante optimal.

Proposition 3. In equilibrium, the firm can make the type $\bar{g}$ contract ex post optimal by the appropriate state contingent wage schedule if the type $\bar{g}$ contract is ex ante optimal.

\section{A.6 Steady State}

Given the equilibrium allocation $\left\{\mathcal{C}^{*}, \mathcal{W}^{*}, x^{*}\right\}$, we consider the flow and distribution of workers at steady state. Let $e_{s}(z)$ and $u(e, z)$ denote the proportion of employment 
in the state $s$ sector and the proportion of unemployed with experience $e$ among trait $z$ workers, respectively. Let define function $\iota_{e}(z)$ and $\iota_{u}(z)$ as

$$
\iota_{e}(z)=\left\{\begin{array}{ll}
1 & \text { if } z \geq z^{e} \\
0 & \text { if } z<z^{e}
\end{array}, \quad \iota_{u}(z)= \begin{cases}1 & \text { if } z \geq z^{u} \\
0 & \text { if } z<z^{u}\end{cases}\right.
$$

Then the flows of workers that apply to type $c$ jobs $\left(z \leq z^{s}\right)$ are given by ${ }^{36}$ (see Figures 6-8)

$$
\begin{aligned}
& \dot{u}(n, z)=d-\left(\phi_{n}+d\right) u(n, z) \\
& \dot{u}(g, z)=\delta_{j} e_{g}(z)-\left(\phi_{g}+\rho+d\right) u(g, z) \\
& \dot{u}(d, z)=\rho\left(u(g, z)+\left(1-\iota_{e}(z)\right) e_{g}(z)\right)+\delta_{j} e_{d}(z)-\left(\phi_{d}+d\right) u(d, z) \\
& \dot{e}_{d}(z)=\iota_{e}(z) \rho e_{g}(z)+\iota_{u}(z) \phi_{d} u(d, z)-\left(\delta_{j}+d\right) e_{d} \\
& \dot{e}_{g}(z)=\sum_{e \in\{n, g\}} \phi_{e} u(e, z)+\left(1-\iota_{u}(z)\right) \phi_{d} u(d, z)-\left(\rho+\delta_{j}+d\right) e_{g}(z)
\end{aligned}
$$

where $\phi_{e}=\phi\left(x^{*}(e, z)\right)$. From (A9), at steady state, we have

$$
\begin{aligned}
u(n, z) & =\frac{d}{d+\phi_{n}} \\
u(g, z) & =\frac{d \delta \phi_{n} \omega_{2}(z)}{\left(d+\phi_{n}\right) \Omega(z)} \\
u(d, z) & =\frac{d \phi_{u} \rho \omega_{1}(z)}{\left(d+\phi_{n}\right) \Omega(z)} \\
e_{d}(z) & =\frac{d \phi_{u} \rho\left[\iota_{e}(z)\left(d+\rho+\phi_{g}\right) \omega_{2}(z)+\iota_{u}(z) \phi_{d} \omega_{1}(z)\right]}{\left(d+\delta_{j}\right)\left(d+\phi_{n}\right) \Omega(z)} \\
e_{g}(z) & =\frac{d\left(d+\rho+\phi_{g}\right) \phi_{n} \omega_{2}(z)}{\left(d+\phi_{n}\right) \Omega(z)}
\end{aligned}
$$

where

$$
\begin{aligned}
\Omega(z) & =(d+\rho)\left(d+\rho+\delta_{j}+\phi_{g}\right) \omega_{2}(z)-\left(1-\iota_{u}(z)\right) \rho \phi_{d} \omega_{1}(z) \\
\omega_{1}(z) & =\left(d+\delta_{j}\right)\left[\left(1-\iota_{e}(z)\right)\left(d+\rho+\phi_{g}\right)+\delta\right]+\delta_{j} \iota_{e}(z)\left(d+\rho+\phi_{g}\right) \\
\omega_{2}(z) & =d\left(d+\delta_{j}+\phi_{d}\right)+\left(1-\iota_{u}(z)\right) \delta \phi_{d}
\end{aligned}
$$

On the other hand, low ability $z>z^{s}$ worker always apply type $s$ job. The steady state distribution for these worker, which is independent of trait of worker, is simply given by

$$
\begin{array}{r}
u(n, z)= \begin{cases}\frac{d+\delta_{s}}{d+\delta_{s}+\phi_{n}} & \text { if } U_{\bar{s}} \geq U_{\hat{s}} \\
\frac{d+\delta_{s}+\rho}{d+\delta_{s}+\rho+\phi_{n}} & \text { if } U_{\bar{s}}<U_{\hat{s}}\end{cases} \\
e_{s}= \begin{cases}\frac{\phi_{n}}{d+\delta_{s}+\phi_{n}} & \text { if } U_{\bar{s}} \geq U_{\hat{s}} \\
\frac{\phi_{n}}{d+\delta_{s}+\rho+\phi_{n}} & \text { if } U_{\bar{s}}<U_{\hat{s}}\end{cases}
\end{array}
$$

where $e_{s}$ is the share of employment at type $s$ job, which is independent of $z$, for $z>z^{S}$.

\footnotetext{
${ }^{36}$ Simple but extremely tedious computations will show that the state variable subsystem is locally stable. It involves confirming for each sub-case the linearized transition matrix to have non-positive eigen values only. We have not encountered any (non-local) instability in numerical computations we used for the analysis in Section 4 of the main text.
} 


\section{A.7 Proofs}

\section{Proof of Proposition 1}

From (A3), we have

$$
\begin{aligned}
U_{c}\left(t, U^{*}\right)= & \max _{w, x} \frac{\phi(x)\left[E_{c}\left(z, w, U^{*}\right)-\kappa(c, t)\right]+I(e) \rho U^{*}(d, z)}{r+d+\phi(x)+I(e) \rho} \\
& \text { s.t. } \quad V_{c}(w, x)=0
\end{aligned}
$$

Note that $\kappa(\bar{g}, t)=\kappa(\hat{g}, t)$ for any $t \in T$. From (A4),

$$
\begin{aligned}
& E_{\bar{g}}\left(z, w, U^{*}\right)=\frac{R_{c} w_{g}+\rho w_{d}+\delta\left(R_{c} U^{*}(g, z)+\rho U^{*}(d, z)\right)}{R_{c}\left(R_{c}+\rho\right)} \\
& E_{\hat{g}}\left(z, w, U^{*}\right)=\frac{w_{g}+\delta U^{*}(g, z)+\rho U^{*}(d, z)}{R_{c}+\rho}
\end{aligned}
$$

Use the zero profit condition to substitute for $w$, we get

$$
U_{c}\left(t, U^{*}\right)=\max _{x} \frac{\phi(x)\left[\tilde{E}_{c}\left(z, x, U^{*}\right)-\kappa(c, t)\right]+I(e) \rho U^{*}(d, z)}{r+d+\phi(x)+I(e) \rho}
$$

where

$$
\begin{aligned}
& \tilde{E}_{\bar{g}}\left(z, x, U^{*}\right)=\frac{\tilde{q}-p_{c}}{R_{c}}+\frac{\delta\left(R_{c} U^{*}(g, z)+\rho U^{*}(d, z)\right)}{R_{c}\left(R_{c}+\rho\right)}-\frac{p_{c}}{\psi(x)}, \\
& \tilde{E}_{\hat{g}}\left(z, x, U^{*}\right)=\frac{q^{c}-p_{c}+\delta U^{*}(g, z)+\rho U^{*}(d, z)}{R_{c}+\rho}-\frac{p_{c}}{\psi(x)}
\end{aligned}
$$

where $\tilde{q} \equiv \frac{R_{j}+\rho \theta}{R_{j}+\rho} q^{c}$. Since we have the following, the proof is complete.

$$
\forall x \quad \tilde{E}_{\bar{g}}\left(z, x, U^{*}\right) \lessgtr \tilde{E}_{\hat{g}}\left(z, x, U^{*}\right) \Leftrightarrow(r+d) U^{*}(d, z) \gtrless \theta q^{c}-p_{c}
$$

\section{Proof of Lemma 1}

The optimal queue length solves the following problem

$$
U_{c}(t, U)=\max _{x} \frac{\phi(x)\left[\tilde{E}_{c}(z, x, U)-\kappa(c, t)\right]+I(e) \rho U(d, z)}{r+d+\phi(x)+I(e) \rho}
$$

where $\tilde{E}_{c}\left(z, x, U^{*}\right)$ is the value of employment that satisfies the zero profit condition. By the first order condition, we have

$\left(r+d+\psi^{\prime}(x)+I(e) \rho\right) p_{c}=\gamma(x)\left[(r+d+I(e) \rho)\left(\tilde{E}_{c}(z, x, U)+p(c) / \psi(x)-\kappa(c, t)\right)-I(e) \rho U(d, z)\right]$ where $\gamma(x)=\psi(x)-\psi^{\prime}(x) / x$. By arranging terms, we get

$$
\tilde{E}_{c}(z, x, U)-\kappa(c, t)=\frac{\Delta(x) x}{\psi(x)} p(c)+\frac{\left[\psi^{\prime}\left(x_{c}(t)\right) / \gamma\left(x_{c}(t)\right)\right] p(c)+I(e) \rho U(d, z)}{r+d+I(e) \rho}
$$

By substituting this into the objective function, we complete the proof of the first half of the proposition.

Second, we will show the second half of the proposition. By using the results above, we write

$$
\begin{aligned}
& U_{c}((g, z), U)=\frac{\Delta\left(x_{c}(g, z)\right) p(c)+\rho U_{c}((d, z), U)}{r+d+\rho}, \\
& U_{c}((d, z), U)=\frac{\Delta\left(x_{c}(d, z)\right) p(c)}{r+d} .
\end{aligned}
$$

Since $U_{c}((g, z), U) \geq U_{c}((d, z), U)$ and $\Delta^{\prime}(x)<0$, we have $x_{c}(g, z) \leq x_{c}(d, z)$. 


\section{Proof of Proposition 2}

Let define $\bar{z}^{u}$ and $\hat{z}^{u}$ by $\tilde{U}_{d}\left(d, \bar{z}^{u}\right)=\tilde{U}_{\bar{g}}\left(d, \bar{z}^{u}\right)$ and $\tilde{U}_{d}\left(d, \hat{z}^{u}\right)=\tilde{U}_{\hat{g}}\left(d, \hat{z}^{u}\right)$, respectively. We will prove that $z \gtrless \bar{z}^{u} \Leftrightarrow \tilde{U}_{d}(d, z) \gtrless \tilde{U}_{\bar{g}}(d, z)$ and that $z \gtrless \hat{z}^{u} \Leftrightarrow \tilde{U}_{d}(d, z) \gtrless$ $\tilde{U}_{\hat{g}}(d, z)$, which will complete the proof if we let $z^{u}=\max \left\{\bar{z}^{u}, \hat{z}^{u}\right\}$.

First, we show that $\partial \tilde{U}_{\bar{g}}\left(d, \bar{z}^{u}\right) / \partial z \leq \partial \tilde{U}_{d}\left(d, \bar{z}^{u}\right) / \partial z<0$, which assures that $z \gtrless \bar{z}^{u} \Leftrightarrow \tilde{U}_{d}(d, z) \gtrless \tilde{U}_{\bar{g}}(d, z)$. Since $I(d)=0$ and $p(c)=p_{c}$ for $c=d, \bar{g}, \hat{g}$, lemma 1 implies $x_{d}\left(d, \bar{z}^{u}\right)=x_{\bar{g}}\left(d, \bar{z}^{u}\right)$ and $x_{\bar{g}}\left(g, \bar{z}^{u}\right) \geq x_{\bar{g}}\left(d, \bar{z}^{u}\right)$. Let $x^{\prime}=x_{d}\left(d, \bar{z}^{u}\right)=$ $x_{\bar{g}}\left(d, \bar{z}^{u}\right)$ and $x^{\prime \prime}=x_{\bar{g}}\left(g, \bar{z}^{u}\right)$.

From (A3) and (A5), $\tilde{U}_{d}(d, z)$ is written by

$$
\begin{aligned}
\tilde{U}_{d}(d, z)= & \max _{w_{d}, x} \frac{w_{d}-R_{c} \epsilon z}{(r+d)\left(R_{c}+\phi(x)\right)} \phi(x) \\
& \text { s.t. } \quad V_{d}(w, x)=0
\end{aligned}
$$

By the envelope theorem, we have

$$
\frac{\partial \tilde{U}_{d}\left(d, \bar{z}^{u}\right)}{\partial z}=-\frac{R_{c} \epsilon \phi\left(x^{\prime}\right)}{(r+d)\left(R_{c}+\phi\left(x^{\prime}\right)\right)}
$$

Similarly, we have

$$
\begin{aligned}
\tilde{U}_{\bar{g}}(d, z)= & \max _{w_{g}, w_{d}, x} \frac{R_{c} w_{g}+\rho w_{d}-R_{c}\left(R_{c}+\rho\right)(\epsilon+m) z+\delta_{c} R_{c} \tilde{U}_{\bar{g}}(g, z)}{(r+d)\left(R_{c}+\rho\right)\left(R_{c}+\phi(x)\right)+\phi(x) \delta_{c} R_{c}} \phi(x) \\
& \text { s.t. } \quad V_{\bar{g}}(w, x)=0
\end{aligned}
$$

and

$$
\begin{aligned}
\tilde{U}_{\bar{g}}(g, z)= & \max _{w_{g}, w_{d}, x} \frac{\phi(x)\left(R_{c} w_{g}+\rho w_{d}-R_{c}\left(R_{c}+\rho\right) \epsilon z\right)+\rho\left[R_{c}\left(R_{c}+\rho\right)+\phi(x) \delta_{c}\right] \tilde{U}_{\bar{g}}(d, z)}{R_{c}(r+d+\rho)\left(R_{c}+\rho+\phi(x)\right)} \\
& \text { s.t. } \quad V_{\bar{g}}(w, x)=0
\end{aligned}
$$

Again by the envelope theorem, we have

$$
\begin{aligned}
& \frac{\partial \tilde{U}_{\bar{g}}\left(d, \bar{z}^{u}\right)}{\partial z}=\frac{-\left(R_{c}+\rho\right) R_{c}(\epsilon+m)+\delta_{c} R_{c} \cdot \partial \tilde{U}_{g^{u}}(g, z) / \partial z}{(r+d)\left(R_{c}+\rho\right)\left(R_{c}+\phi\left(x^{\prime}\right)\right)+\phi\left(x^{\prime}\right) \delta_{c} R_{c}} \phi\left(x^{\prime}\right) \\
& \frac{\partial \tilde{U}_{\bar{g}}\left(g, \bar{z}^{u}\right)}{\partial z}=\frac{-R_{c}\left(R_{c}+\rho\right) \epsilon \phi\left(x^{\prime \prime}\right)+\rho\left[R_{c}\left(R_{c}+\rho\right)+\phi\left(x^{\prime \prime}\right) \delta_{c}\right] \partial \tilde{U}_{g^{u}}(d, z) / \partial z}{R_{c}(r+d+\rho)\left(R_{c}+\rho+\phi\left(x^{\prime \prime}\right)\right)}
\end{aligned}
$$

By substituting (A11) into (A10), we have

$$
\frac{\partial \tilde{U}_{\bar{g}}(d, z)}{\partial z}=-\frac{R_{c} \phi\left(x^{\prime}\right)\left[(r+d+\rho)\left(R_{c}+\rho+\phi\left(x^{\prime \prime}\right)\right)(\epsilon+m)+\delta_{c} \phi\left(x^{\prime \prime}\right) \epsilon\right]}{(r+d)\left[(r+d+\rho)\left(R_{c}+\phi\left(x^{\prime}\right)\right)\left(R_{c}+\rho+\phi\left(x^{\prime \prime}\right)\right)+\delta \phi\left(x^{\prime}\right)\left(R_{c}+\phi\left(x^{\prime \prime}\right)\right)\right]}
$$

Taking the ratio

$\frac{\partial \tilde{U}_{\bar{g}}\left(d, \bar{z}^{u}\right) / \partial z}{\partial \tilde{U}_{d}\left(d, z_{u}^{u}\right) / \partial z}=\frac{(r+d+\rho)\left(R_{c}+\phi\left(x^{\prime}\right)\right)\left(R_{c}+\rho+\phi\left(x^{\prime \prime}\right)\right)(\epsilon+m) / \epsilon+\delta_{c} \phi\left(x^{\prime \prime}\right)\left(R_{c}+\phi\left(x^{\prime}\right)\right)}{(r+d+\rho)\left(R_{c}+\phi\left(x^{\prime}\right)\right)\left(R_{c}+\rho+\phi\left(x^{\prime \prime}\right)\right)+\delta_{c} \phi\left(x^{\prime}\right)\left(R_{c}+\phi\left(x^{\prime \prime}\right)\right)}$

Since $m \geq 0$ and $x^{\prime \prime} \geq x^{\prime}$, the numerator is not less than the denominator. Therefore, we have $\partial \tilde{U}_{\bar{g}}\left(d, \bar{z}^{u}\right) / \partial z \leq \partial \tilde{U}_{d}\left(d, \bar{z}^{u}\right) / \partial z<0$.

Since we can also show $\partial \tilde{U}_{\hat{g}}\left(d, \hat{z}^{u}\right) / \partial z \leq \partial \tilde{U}_{d}\left(d, \hat{z}^{u}\right) / \partial z<0$ by the same procedure, the first part of the proposition is proved.

The second part of the proposition is obvious because $\partial \tilde{U}_{c}(d, z) / \partial z$ is non-positive for $c=d, \bar{g}, \hat{g}$. 


\section{Proof of Proposition 3}

If type $\bar{g}$ contract is ex ante optimal, we have $(r+d) U^{*}(d, z) \leq \theta q^{c}-p_{c}$ from Proposition 1 . Therefore by setting $w_{d}$ so as to satisfy (8), the firm can make the contract ex post optimal.

\section{A.8 The Optimal Queue Lengths}

We briefly indicate how to solve for the optimal queue lengths. As in the proof of Lemma 1, the optimal queue length satisfies

$$
\begin{aligned}
& \left(r+d+\psi^{\prime}(x)+I(e) \rho\right) p_{c} \\
& =\gamma(x)\left[(r+d+I(e) \rho)\left(\tilde{E}_{c}(z, x, U)+p(c) / \psi(x)-\kappa(c, t)\right)-I(e) \rho U(d, z)\right]
\end{aligned}
$$

As an example, we consider the case in which the unemployed trained workers choose to stay in the same industry, i,e, $z \in\left(z^{s}, z^{e}\right)$. The other cases can be solved in a similar fashion.

Let $x_{d}^{*}$ be the optimal queue length for type $d$ worker. Since the unemployed worker chooses the type $d$ contract, $c=d$ and $\kappa(c, t)=\epsilon z$, then $x_{d}$ solves

$$
\begin{aligned}
& \left(r+d+\psi^{\prime}\left(x_{d}^{*}\right)\right) p_{c} \\
& =\gamma\left(x_{d}^{*}\right)(r+d)\left[\left(\tilde{E}_{d}(z, x, U)+p(c) / \psi\left(x_{d}^{*}\right)-\epsilon z\right]\right. \\
& =\gamma\left(x_{d}^{*}\right)(r+d)\left[\frac{\theta q^{c}-p_{c}+\delta_{c} U^{*}(d, z)}{R_{c}}-\epsilon z\right]
\end{aligned}
$$

From Lemma 1, we have $U^{*}(t)=\frac{\Delta\left(x^{*}(t)\right) p(c)+I(e) \rho U^{*}(d, z)}{r+d+I(e) \rho}$, define, thus

$$
\begin{aligned}
& \left(r+d+\psi^{\prime}\left(x_{d}^{*}\right)\right) p_{c} \\
& =\gamma\left(x_{d}^{*}\right)(r+d)\left[\frac{\theta q^{c}-p_{c}}{R_{c}}+\frac{\delta_{c}}{R_{c}} \frac{\Delta\left(x_{d}^{*}\right) p_{c}}{r+d}-\epsilon z\right]
\end{aligned}
$$

Since $\Delta(x)=\psi^{\prime}(x) / \gamma(x)$, we have

$$
p_{c}\left(R_{c}+\psi^{\prime}\left(x_{d}^{*}\right)\right)=\gamma\left(x_{d}^{*}\right)\left(\theta q^{c}-p_{c}\right)
$$

On the other hand, the optimal queue length for type $g$ worker, $x_{g}^{*}$, satisfies

$$
\begin{aligned}
& \left(r+d+\psi^{\prime}\left(x_{g}^{*}\right)+\rho\right) p_{c} \\
& =\gamma\left(x_{g}^{*}\right)\left[(r+d+\rho)\left(\tilde{E}_{g^{u}}(z, x, U)+p(c) / \psi\left(x_{g}^{*}\right)-\epsilon z\right)-\rho U^{*}(d, z)\right] \\
& =\gamma\left(x_{g}^{*}\right)\left[(r+d+\rho)\left(\frac{\tilde{q}-p_{c}}{R_{c}}+\frac{\delta_{c}\left(R_{c} U^{*}(g, z)+\rho U^{*}(d, z)\right)}{R_{c}\left(R_{c}+\rho\right)}-\epsilon z\right)-\rho U^{*}(d, z)\right] \\
& =\gamma\left(x_{g}^{*}\right)\left[(r+d+\rho)\left(\frac{\tilde{q}-p_{c}}{R_{c}}-\epsilon z\right)+\frac{\delta_{c} R_{c} \Delta\left(x_{g}^{*}\right) p_{c}-\rho(r+d)(r+d+\rho) U^{*}(d, z)}{R_{c}\left(R_{c}+\rho\right)}\right]
\end{aligned}
$$

By rearranging terms, we have

$$
R_{c}\left(R_{c}+\rho+\psi^{\prime}\left(x_{g}^{*}\right)\right) p_{c}=\gamma\left(x_{g}^{*}\right)\left[\left(R_{c}+\rho\right)\left(\tilde{q}-p_{c}-R_{c} \epsilon z\right)-\rho \Delta\left(x_{d}^{*}\right) p_{c}\right]
$$

Similarly, the optimal queue length for type $n$ worker, $x_{n}^{*}$, satisfies

$$
\begin{aligned}
& \left(r+d+\psi^{\prime}\left(x_{n}^{*}\right)\right) p_{c} \\
& =\gamma\left(x_{n}^{*}\right)(r+d)\left[\tilde{E}_{g^{u}}(z, x, U)+p(c) / \psi\left(x_{n}^{*}\right)-z\right] \\
& =\gamma\left(x_{n}^{*}\right)(r+d)\left[\frac{\tilde{q}-p_{c}}{R_{c}}+\frac{\delta_{c}\left(R_{c} U^{*}(g, z)+\rho U^{*}(d, z)\right)}{R_{c}\left(R_{c}+\rho\right)}-z\right] \\
& =\gamma\left(x_{n}^{*}\right)(r+d)\left[\left(\frac{\tilde{q}-p_{c}}{R_{c}}-z\right)+\delta_{c} \frac{(r+d) R_{c} \Delta\left(x_{g}^{*}\right) p_{c}+\rho\left(r+d+\rho+R_{c}\right) \Delta\left(x_{d}^{*}\right) p_{c}}{R_{c}\left(R_{c}+\rho\right)(r+d+\rho)(r+d)}\right]
\end{aligned}
$$


Thus, we have

$$
\begin{aligned}
& \left(r+d+\psi^{\prime}\left(x_{n}^{*}\right)\right) p_{c} \\
& =\gamma\left(x_{n}^{*}\right)\left[(r+d)\left(\frac{\tilde{q}-p_{c}}{R_{c}}-z\right)+\delta_{c} \frac{(r+d) R_{c} \Delta\left(x_{g}^{*}\right) p_{c}+\rho\left(r+d+\rho+R_{c}\right) \Delta\left(x_{d}^{*}\right) p_{c}}{R_{c}\left(R_{c}+\rho\right)(r+d+\rho)}\right]
\end{aligned}
$$

(The end of the Appendix)

\section{References}

[1] Anton Braun, R., J. Esteban-Pretel, T. Okada, and N. Sudou (2006) "A comparison of the Japanese and US business cycles," Japan and The World Economy,Vol. 18, No. 4, pp. 441-463.

[2] Ariga, K., G. Brunello and Y. Ohkusa (2000), Internal Labor Market in Japan, Cambridge University Press, Cambridge.

[3] Ariga, K., M. Kurosawa, and F. Ohtake (2006) "Human Resource Management Practices and Firm Level Training," in Hayashi, F. (eds) Keizai Teitai no Genin to Seido, (in Japanese) Keiso-Syobou, Tokyo.

[4] Ariga, K., M. Kurosawa, F. Ohtake, and M. Sasaki (2009), "Productivity and Job Training: Evidence from Japanese Automobile Makers," a paper presented at Second Trans-Pacific Labor Seminar, Tokyo.

[5] Bassanini, A., A. L. Booth, G. Brunello, M. De Paola, and E. Leuven (2005), "Workplace Training in Europe," IZA Discussion Paper 1640

[6] Caballero, R.J., T. Hoshi, and A.K. Kashyap (2008) "Zombie lending and depressed restructuring in Japan," American Economic Review, Vol. 98, pp. 19431977.

[7] Esteban-Pretel, R. Nakajima, and R. Tanaka (2009) "Are Contingent Jobs Dead Ends or Stepping Stones to Regular Jobs? Evidence from a Structural Estimation," RIETI working paper No. 09-E-002.

[8] Fujita, S. and G. Ramey (2007) "Job matching and propagation," Journal of Economic Dynamics and Control, Vol. 31, No. 11, pp. 3671-3698.

[9] Fukao, K., Y. Kim, and H. U. Kwon (2008) 'Why has the Japanese TFP growth recovered?," (in Japanese) RIETI, DP, 08-J-050.

[10] Fukao, K. and H. U. Kwon (2006) "Why Did Japan's TFP Growth Slow Down in the Lost Decade? An Empirical Analysis Based on Firm-Level Data of Manufacturing Firms," Japanese Economic Review, Vol. 57, No. 2, pp. 195-228.

[11] Fukao, K. and M. Otaki (1993) "Accumulation of Human Capital and the Business Cycle," Journal of Political Economy, Vol. 101, No. 1, p. 73-99.

[12] Genda, Y., A. Kondo, and S. Ohta (forthcoming) "Long-term effects of a recession at labor market entry in Japan and the United States," forthcoming in Journal of Human Resources.

[13] Genda, Y. and M. Kurosawa (2001) "Transition from School to Work in Japan," Journal of The Japanese and International Economies, Vol. 15, No. 4, pp. 465488.

[14] Genda, Y., S. Ohta, and H. Teruyama (2008) "The Japanese Unemployment after 90's," (in Japanese) Bank of Japan, DP, 08-J-4.

[15] Hornstein, A., P Krusell, and G.L. Violante (2007) "Technology-Policy Interaction in Frictional Labour-Markets," Review of Economic Studies, Vol. 74, No. 4, pp. 1089-1124.

[16] Ito, K and S. Lechevalier (2008) "The evolution of the productivity dispersion of firms-A reevaluation of its determinants in the case of Japan," RIETI, DP, 08-E-014. 
[17] Kato, T. and R. Kambayashi "The Japanese Employment System after the Bubble Burst: New Evidence." this conference.

[18] Kambayashi, R. and Y. Ueno (2006) "Vacancy Market Structure and Matching Efficiency," "ESRI, DP, No. 160.

[19] Kano, S. and M. Ohta (2005) "Estimating a matching function and regional matching efficiencies: Japanese panel data for 1973-1999," Japan and The World Economy, Vol. 17, No. 1, pp. 25-41.

[20] Koike, K. (2005) Economics of Work (in Japanese), Toyo-Kiezai, Tokyo.

[21] Kondo, A. (2007) "Does the first job really matter? State dependency in employment status in Japan," Journal of The Japanese and International Economies, Vol. 21, No. 3, pp. 379-402.

[22] Kuroda, S. (2003) "Analysis of Changes in Japan's Unemployment Rate Using Gross Flow Data," Monetary and Economic Studies, Vol. 21, pp. 69-104.

[23] Miyagawa, T. (2005), Economics of longrun stagnation [Choki Teitai no Keizaigaku] (in Japanese), University of Tokyo Press

[24] Miyagawa, T., Y. Sakuragawa, and M. Takizawa (2006) "The impact of technology shocks on the Japanese business cycle - An empirical analysis based on Japanese industry data," Japan and The World Economy, Vol. 18, No. 4, pp. 401-417.

[25] Moen, E.R. and A. Rosen (2004) "Does Poaching Distort Training?" Review of Economic Studies, Vol. 71, No. 4, pp. 1143-1162.

[26] Mortensen, D.T. and C.A. Pissarides (1998) "Technological Progress, Job Creation, and Job Destruction," Review of Economic Dynamics, Vol. 1, No. 4, pp. 733-753.

[27] Muramatsu, K., 1995, "Employment Adjustments in Japan: A Review," in Inoki and Higuchi (eds.) The Japanese Employment System and the Labor Market (in Japanese), Nihon-Keizai-Shinbun, Tokyo

[28] Nishimura, K.G., and K. Minetaki (2004) Information Communication Technology and the Japanese Economy [Jyoho Kijyutsu Kakushin to Nhon Keizai] (in Japanese), Yuhikaku

[29] Ohtake, F. (2005) A Study of Inequality in Japan (in Japanese), Toyo-Kiezai, Tokyo.

[30] Shinada, N. (2003) "Decline in Productivity in Japan and Disparities between Firms in the 1990s: An Empirical Approach Based on Data Envelopment Analysis", Development Bank of Japan Research Report, No.38, Development Bank of Japan, Tokyo. 


\begin{tabular}{||l|l|l||}
\hline \hline & \multicolumn{2}{|l||}{ industry type } \\
\hline Worker type & $g$-sector & $d$-sector \\
\hline not trained & $(n, g)$ & not active \\
\hline trained in the same industry & $(g, g)$ & $(d, d)$ if $z \geq z^{u}$ \\
\hline trained elsewhere & $(d, g)$ if $z \leq z^{u}$ & not active \\
\hline \hline
\end{tabular}

Table 1: Table of sub-markets

\begin{tabular}{crl}
\hline \hline parameter & value & discription \\
\hline$r$ & 0.005 & interest rate (annual 2\%) \\
$d$ & 0.0063 & exiting rate (annual 2.5\%) \\
$\mu_{z}$ & 9.0 & mean of training cost \\
$\sigma_{z}$ & 12.1 & standard deviation of training cost \\
$\epsilon$ & 0.15 & across firm mobility \\
$m$ & 0.42 & across industry mobility cost \\
$\rho$ & 0.006 & the frequency of productivity shock (annual 2.4\%) \\
$\theta$ & 0.88 & the scale of negative shock \\
$\delta^{j}$ & 0.003 & separation rate of type j job (annual 1.2\%) \\
$\delta^{s}$ & 0.037 & separation rate of type s job (annual 14.8\%) \\
$q^{c}$ & 1.5 & productivity of complicated task \\
$q^{s}$ & 1.0 & productivity of simple task \\
$p^{j}$ & 0.42 & rental cost of type j capital \\
$p^{s}$ & 0.23 & rental cost of type s capital \\
$A$ & 0.48 & efficiency of matching function \\
$\eta$ & 0.3 & parameter of matching function \\
\hline \hline
\end{tabular}

Table 2: Benchmark Parameter Values 


\begin{tabular}{lrrrr}
\hline \hline & benchmark & $\theta$ shock & $\rho$ shock & both shock \\
\hline Unemployment rate (\%) & 3.1 & 3.6 & 3.6 & 4.5 \\
Vacancy /Unemployment & 1.00 & 1.01 & 1.00 & 1.02 \\
Thresholds & & & & \\
$z^{s}$ & 26.7 & 25.3 & 25.1 & 22.6 \\
$z^{u}$ & 24.6 & & 18.2 & \\
$z^{e}$ & 11.8 & 18.0 & 7.6 & 12.4 \\
Job Finding Rate & 0.48 & 0.48 & 0.48 & 0.48 \\
$\quad$ part-time job & 0.51 & 0.51 & 0.51 & 0.51 \\
$\quad$ full-time job & 0.47 & 0.47 & 0.46 & 0.46 \\
Annual worker turnover rate (full-time \%) & 9.9 & 11.3 & 10.6 & 13.1 \\
Annual worker turnover rate (part-time \%) & 39.4 & 39.4 & 44.2 & 44.2 \\
Share of accessions with industry change (\%) & 60.0 & 64.9 & 69.1 & 77.7 \\
Employment share (\%) & & & & \\
$\quad$ at part-time job & 8.4 & 10.6 & 10.8 & 15.7 \\
$\quad$ at full-time job in d & 17.5 & 7.1 & 35.1 & 19.3 \\
$\quad$ at full-time job in g & 74.1 & 82.3 & 54.2 & 65.0 \\
Gross output & 1.38 & 1.38 & 1.33 & 1.31 \\
Aggregate training cost & 0.085 & 0.091 & 0.079 & 0.084 \\
Average value of untrained & 74.1 & 73.6 & 71.5 & 70.4 \\
\hline \hline
\end{tabular}

Table 3: Steady States before and after Two Macro Shocks

\begin{tabular}{lrr}
\hline \hline & $\theta$ shock & \\
\hline & $50 \%$ benchmark & $75 \%$ benchmark \\
\hline Unemployment rate & 1.5 & 1.75 \\
Employment share (\%) & & \\
at part-time job & 27 & 50 \\
at full-time job in g & 0.5 & 0.5 \\
\hline \hline \multicolumn{3}{c}{$\rho$ shock } \\
\hline Unemployment rate & $50 \%$ benchmark & $75 \%$ benchmark \\
Employment share (\%) & 1 & 24 \\
at part-time job & 29 & 56 \\
at full-time job in g & 9 & 18 \\
\hline \hline
\end{tabular}

Table 4: Transition paths after macro shocks (unit: year) 


\begin{tabular}{|c|c|c|c|c|c|}
\hline & both shock & $\begin{array}{r}\text { capital } \\
\text { subsidy }\end{array}$ & firing cost & $\begin{array}{r}\text { training } \\
\text { (untrained) }\end{array}$ & $\begin{array}{r}\text { training } \\
\text { (trained) }\end{array}$ \\
\hline Unemployment rate & 4.5 & -0.2 & -0.2 & -0.2 & +0.1 \\
\hline Vacancy /Unemployment & 1.02 & & & -0.01 & \\
\hline Job Finding Rate & 0.48 & & & & \\
\hline \multicolumn{6}{|l|}{ Thresholds } \\
\hline $\begin{array}{l}z^{s} \\
z^{u}\end{array}$ & 22.6 & +0.3 & & +0.9 & \\
\hline$z^{e}$ & 12.4 & -0.9 & -1.5 & & +1.1 \\
\hline Annual worker turnover (full-time \%) & 13.1 & -0.4 & -0.7 & -0.1 & +0.6 \\
\hline Change of industry $(\%)$ & 77.7 & -0.5 & -0.8 & -0.1 & +0.5 \\
\hline \multicolumn{6}{|l|}{ Employment share (\%) } \\
\hline at part-time job & 15.7 & -0.8 & & -1.9 & \\
\hline at full-time job in $\mathrm{d}$ & 19.3 & +2.6 & +3.4 & +1.1 & -2.6 \\
\hline at full-time job in $\mathrm{g}$ & 65.0 & -1.8 & -3.4 & +0.8 & +2.5 \\
\hline Gross output & 1.31 & & & +0.01 & +0.01 \\
\hline Average value of untrained & 70.4 & -0.1 & -0.3 & +0.2 & \\
\hline
\end{tabular}

Table 5: Policy effects

Figures show net changes from the benchmark values in the first column

\begin{tabular}{lrrr}
\hline \hline & benchmark & Case 1 & Case 2 \\
\hline & $\epsilon=.15$ & $\epsilon=0$ & $\epsilon=.15$ \\
& $m=.42$ & $m=.42$ & $m=.21$ \\
\hline Unemployment rate & 1.4 & 1.5 & 1.6 \\
Annual worker turnover (full-time \%) & 3.2 & 4.2 & 4.7 \\
Change of location (\%) & 17.7 & 16.3 & 14.9 \\
Employment share (\%) & & & \\
$\quad$ at part-time job & 7.3 & 7.2 & 6.7 \\
at full-time job in d & 1.8 & -1.0 & -2.1 \\
at full-time job in g & -9.1 & -6.2 & -4.6 \\
Gross output (\% change) & -4.9 & -4.3 & -3.9 \\
Average value of untrained (\% change) & -5.0 & -4.6 & -4.2 \\
\hline \hline
\end{tabular}

Table 6: The impact of Macro shocks 


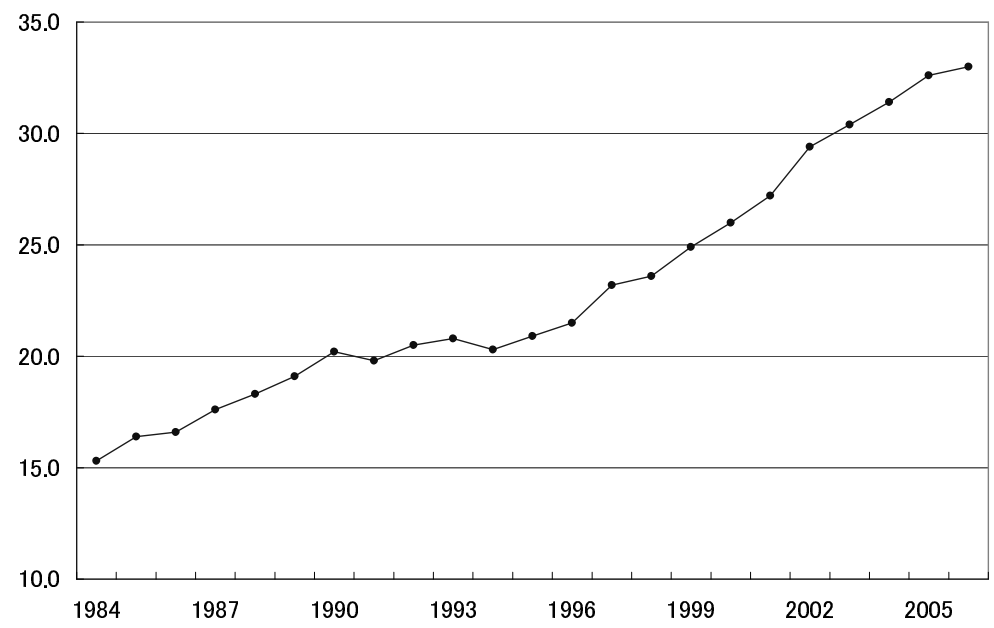

Figure 1: The Share of Temporary and Parttime Employment 


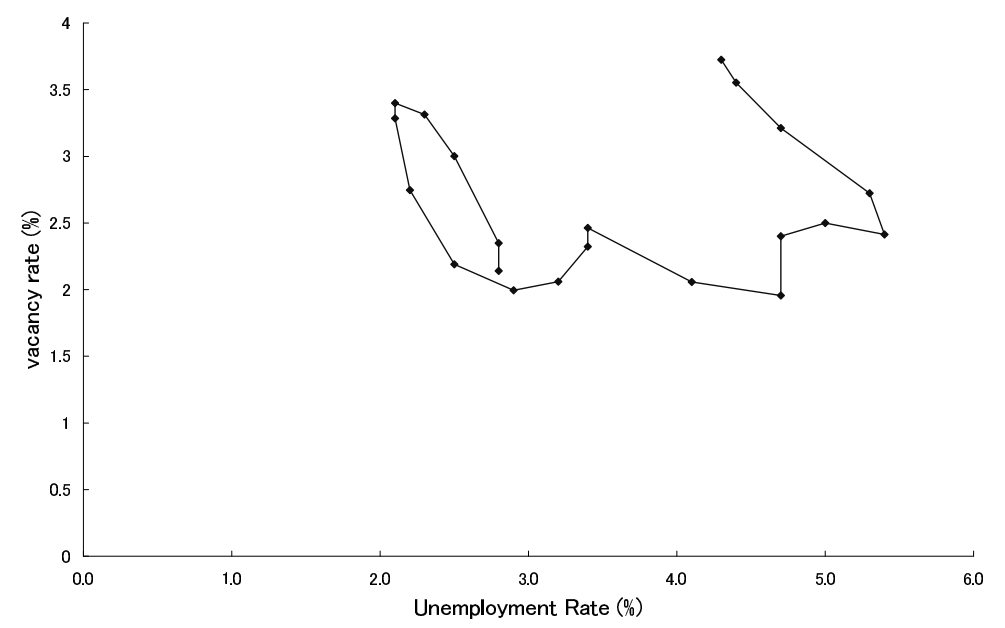

Figure 2: Beveridge Curve

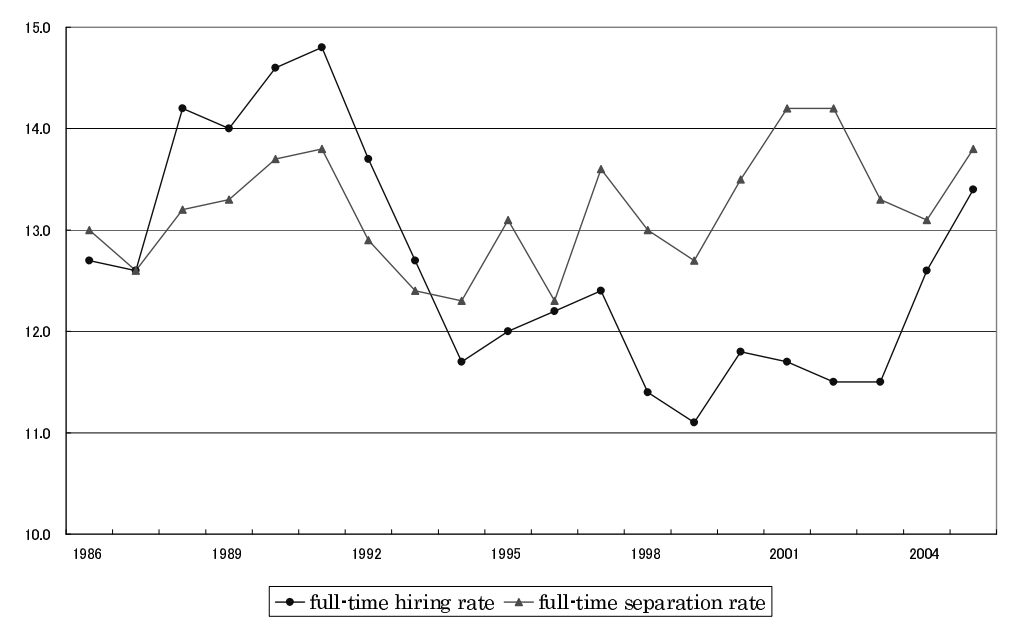

Figure 3: Job Accession and Separations: Full time employees 


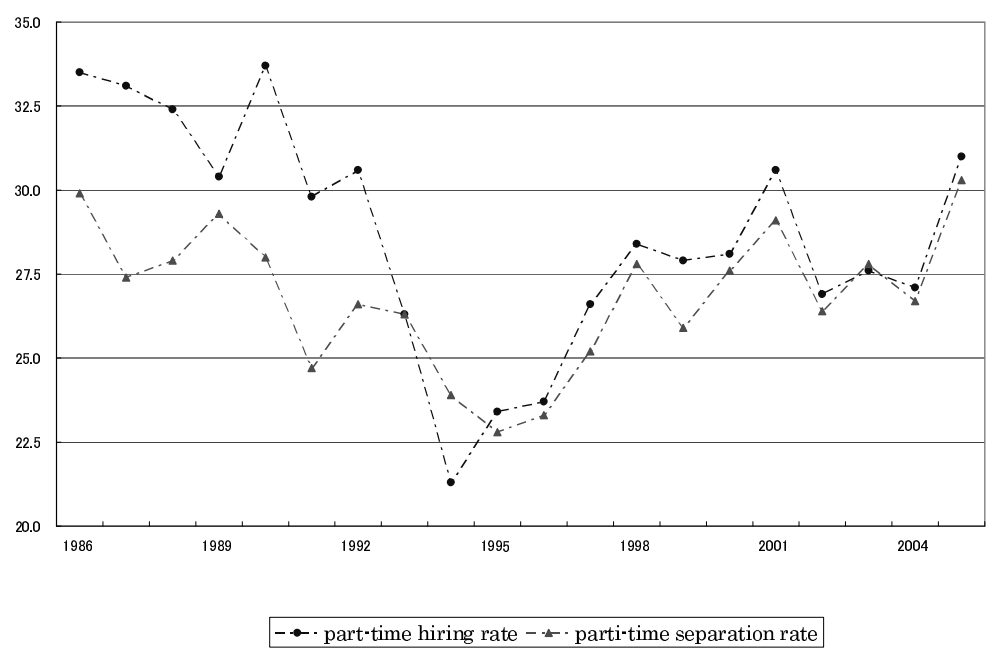

Figure 4: Job Accession and Separations: Part time employees 


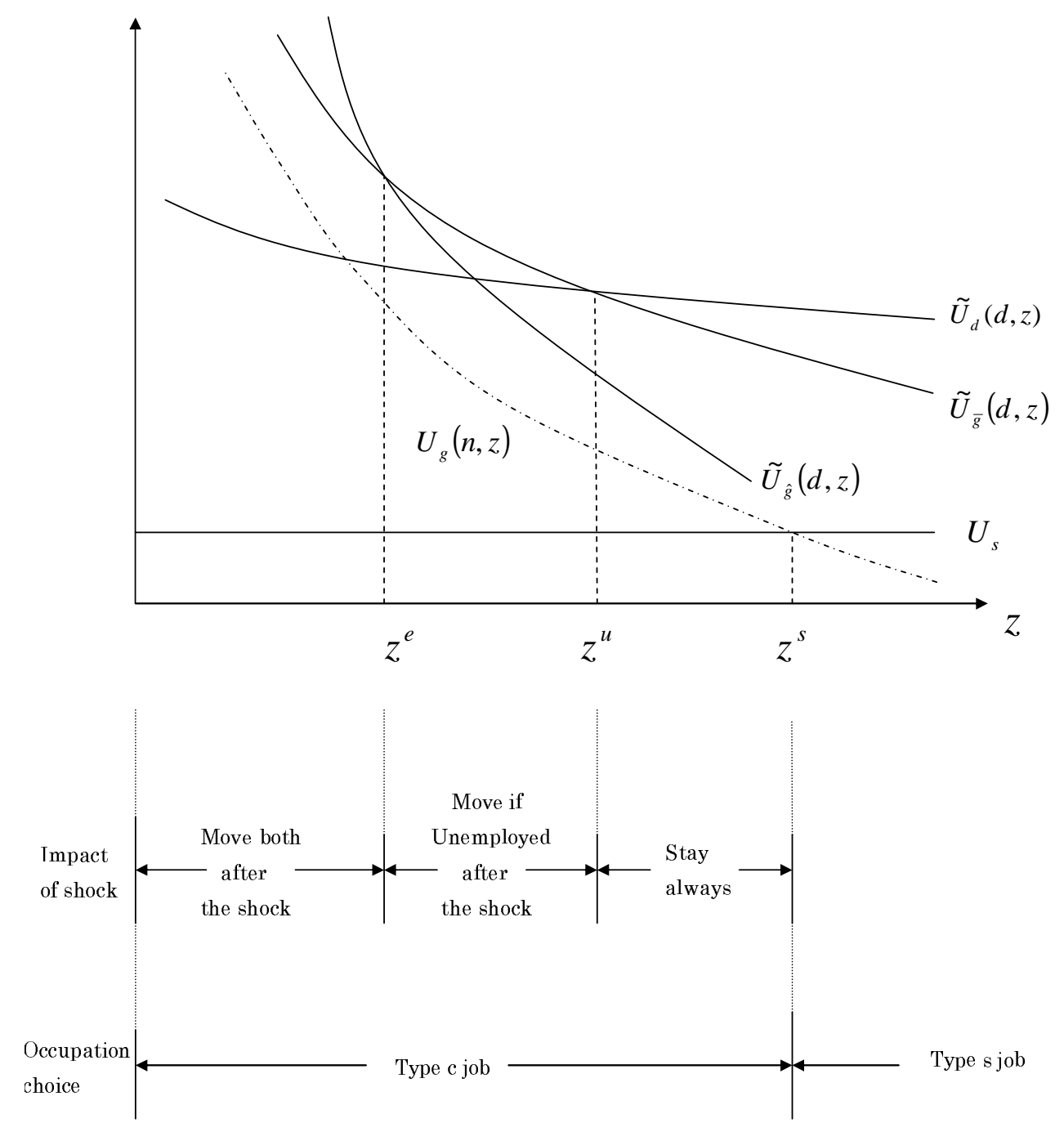

Figure 5: Optimal Job Search Strategy 


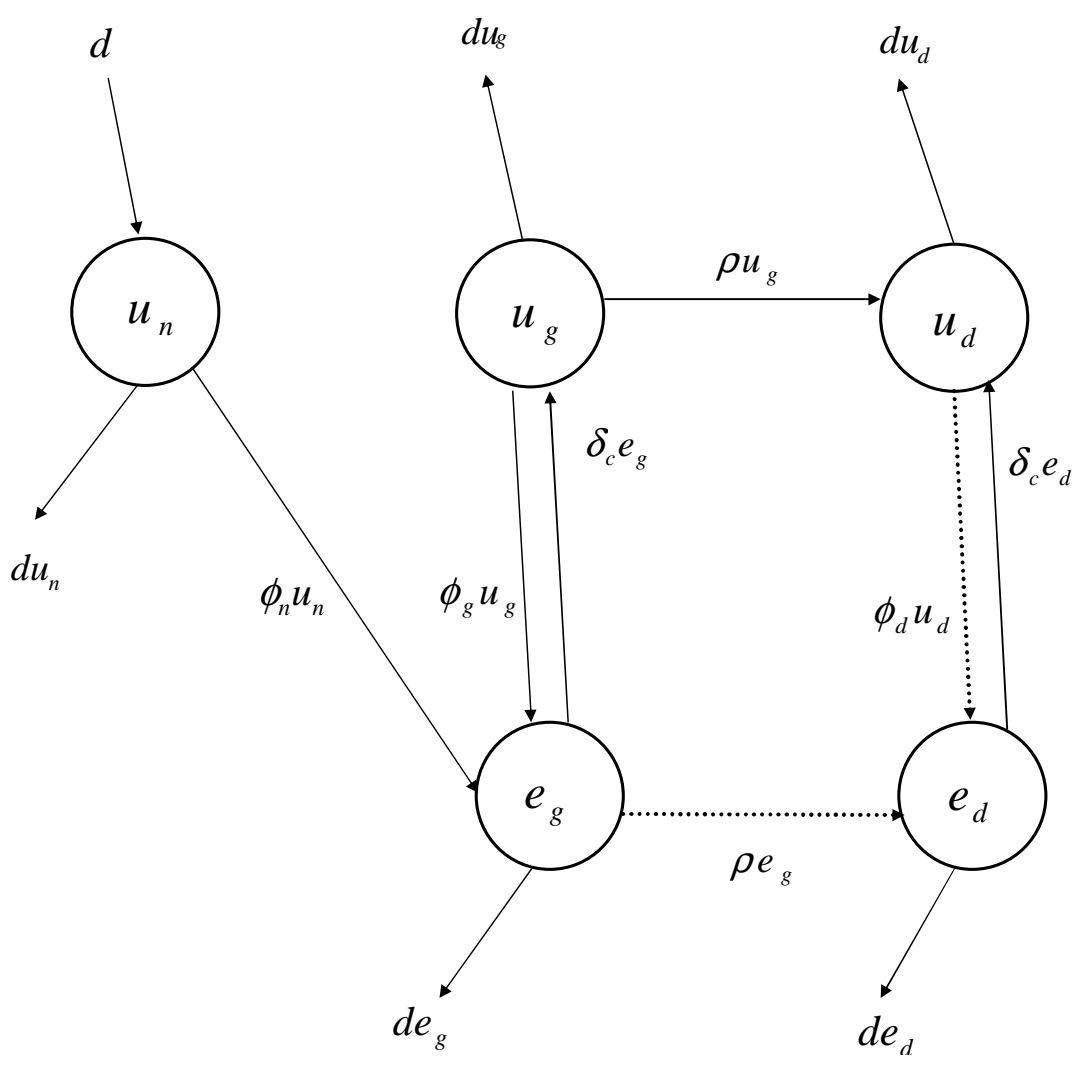

Figure 6: Worker flows $z^{u}<z<z^{s}$ 


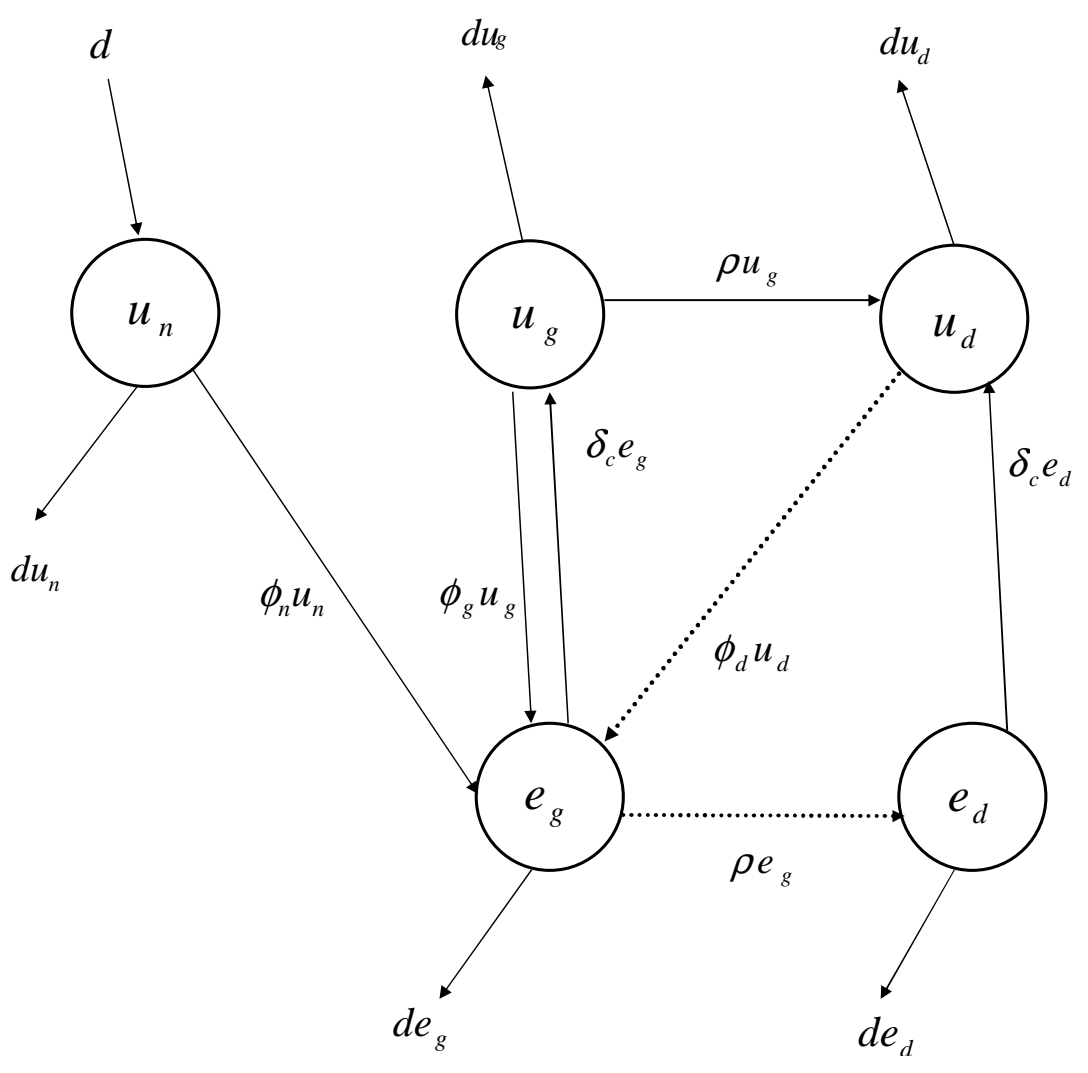

Figure 7: Worker Flows $z^{e}<z<z^{u}$ 


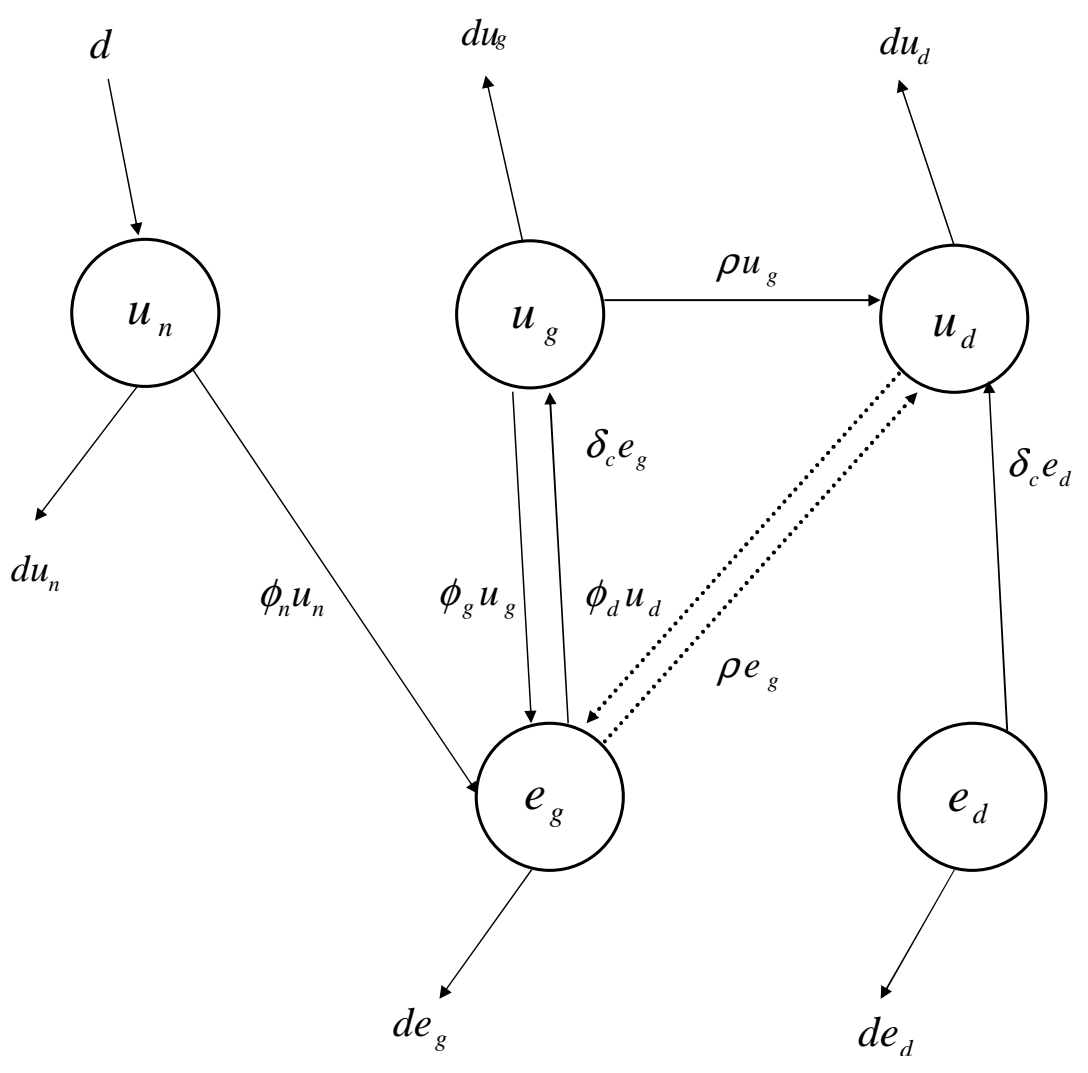

Figure 8: Worker Flows $z<z^{e}$ 


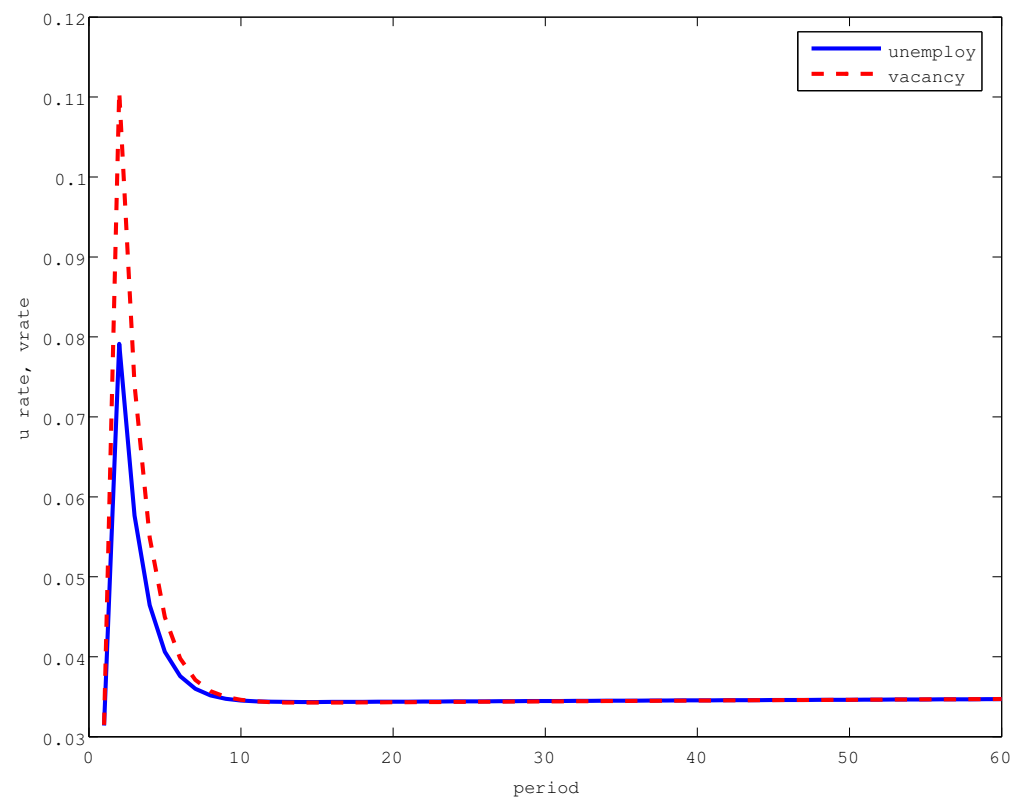

Figure 9: Simulated Dynamics of Unemployed and Vacancy: $\theta$ shock 


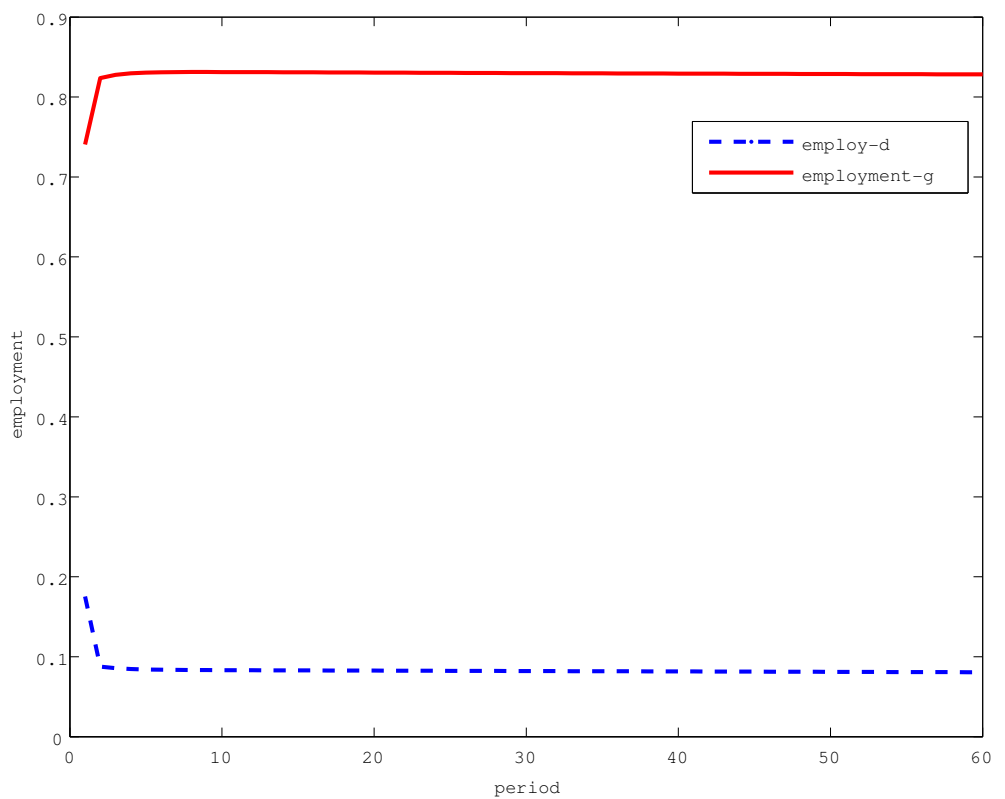

Figure 10: Simulated Dynamics of Employment Composition: $\theta$ shock 


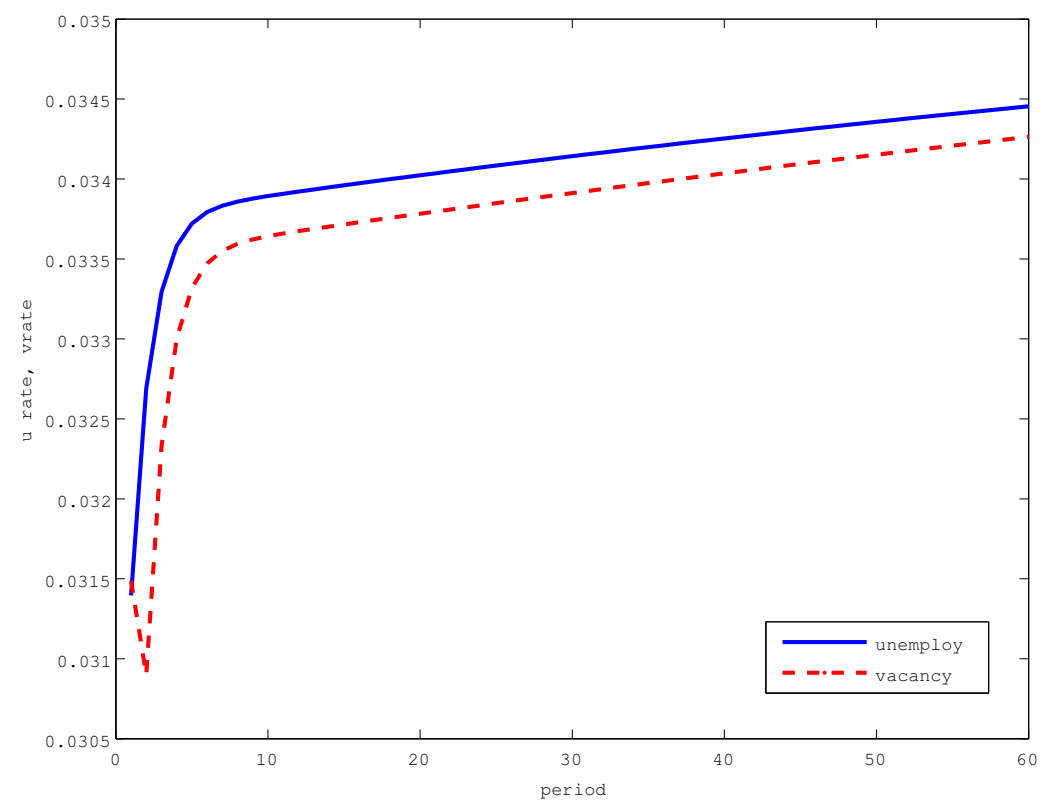

Figure 11: Simulated Dynamics of Unemployed and Vacancy: $\rho$ shock 


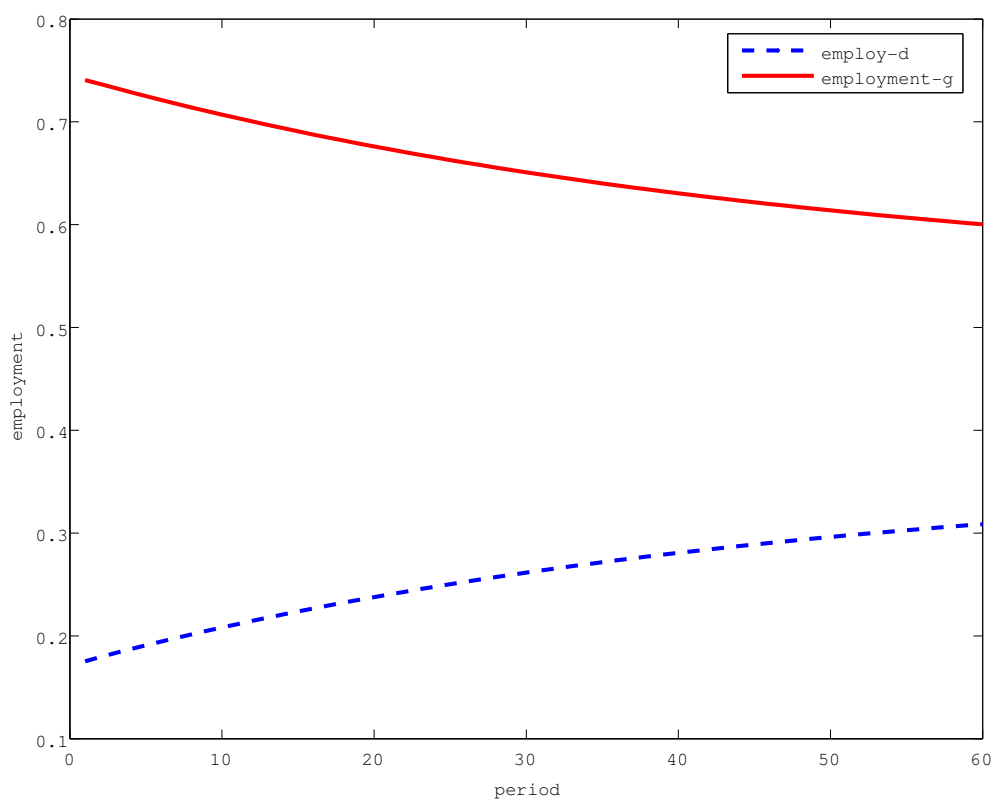

Figure 12: Simulated Dynamics of Employment Composition: $\rho$ shock 


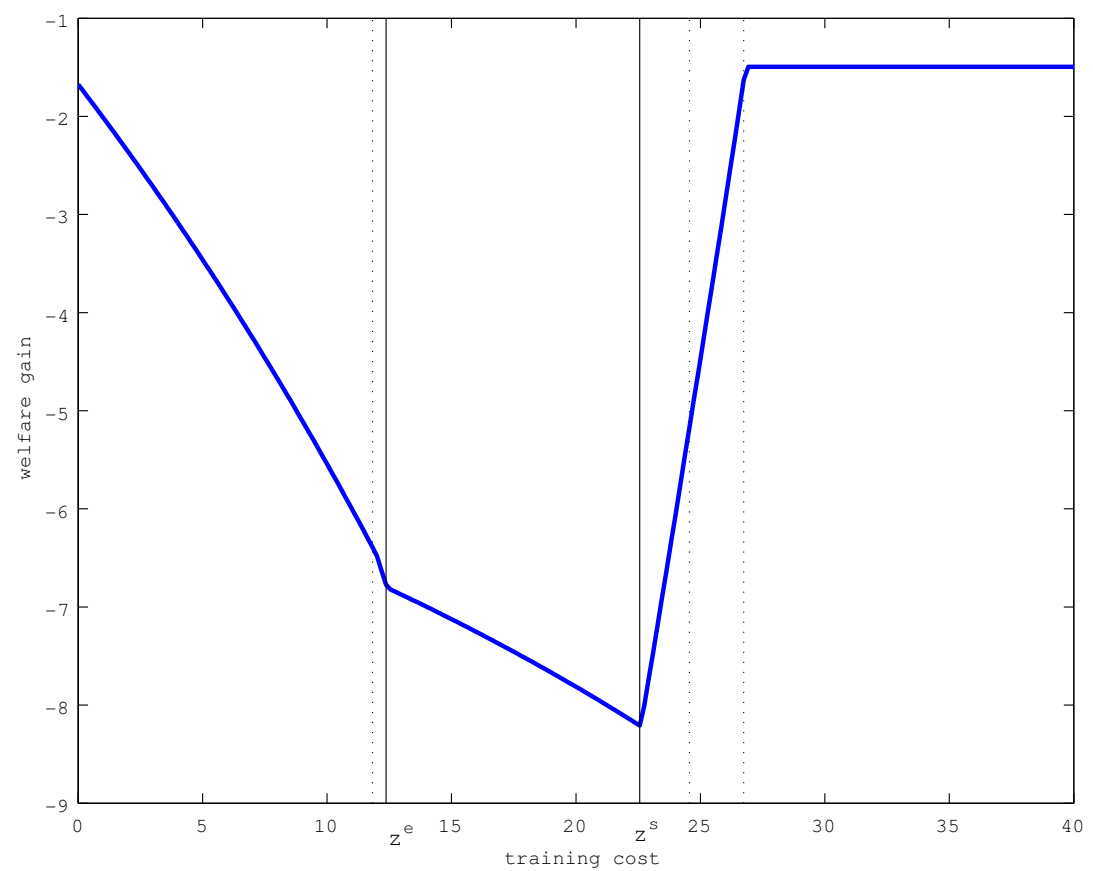

Figure 13: Welfare loss by combined macro shocks (\%) Dashed (real) lines indicate threshold values before (after) the macro shocks. 


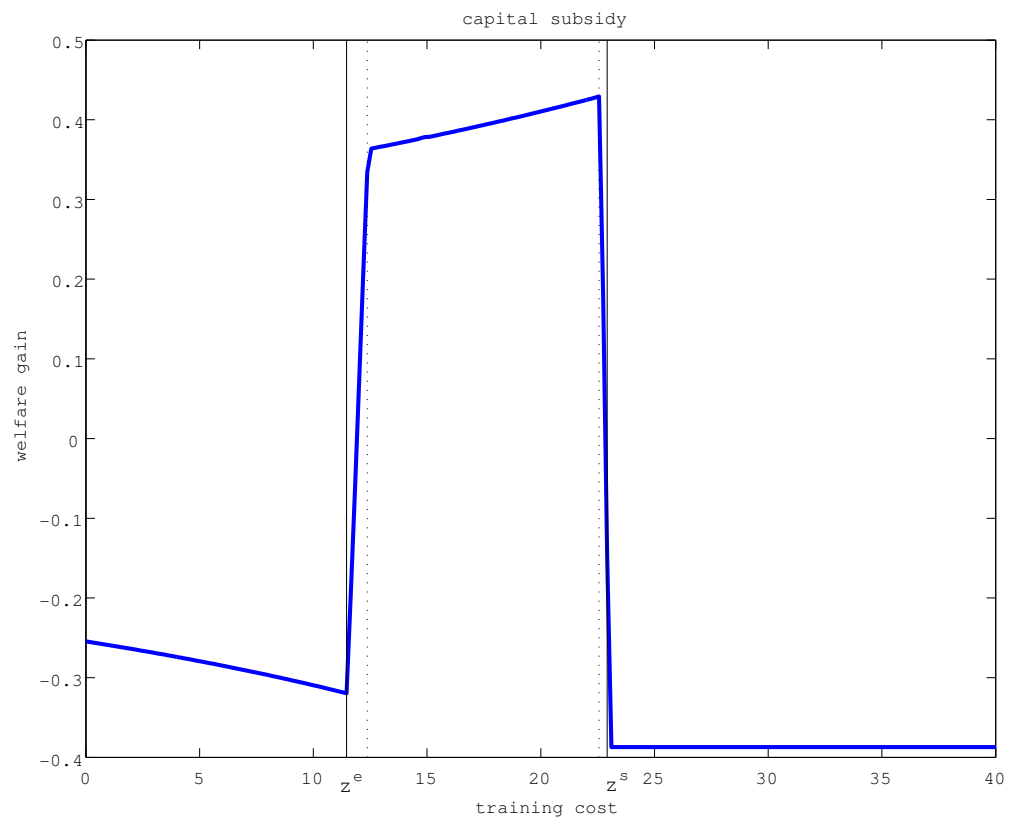

Figure 14: Net Welfare gains: Capital subsidy (\%)

In Figures 14 through 17, dashed (real) lines indicate threshold values without (with) respective policy injections. 


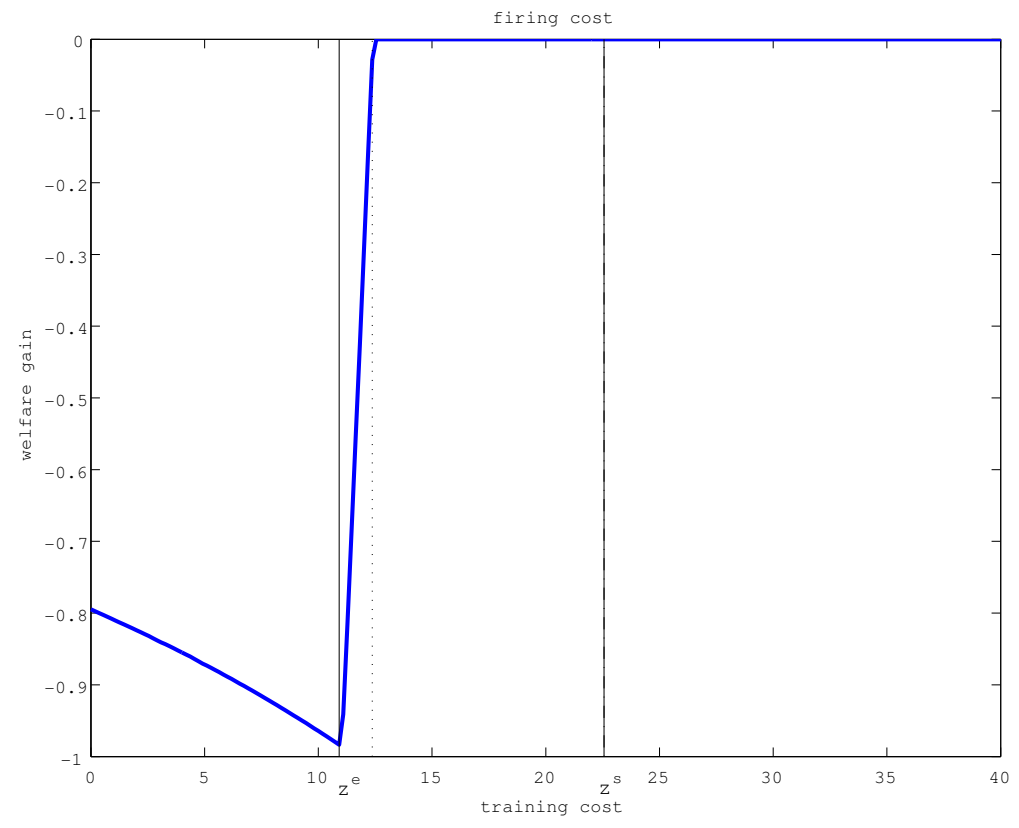

Figure 15: Net Welfare gains: Firing cost (\%) 


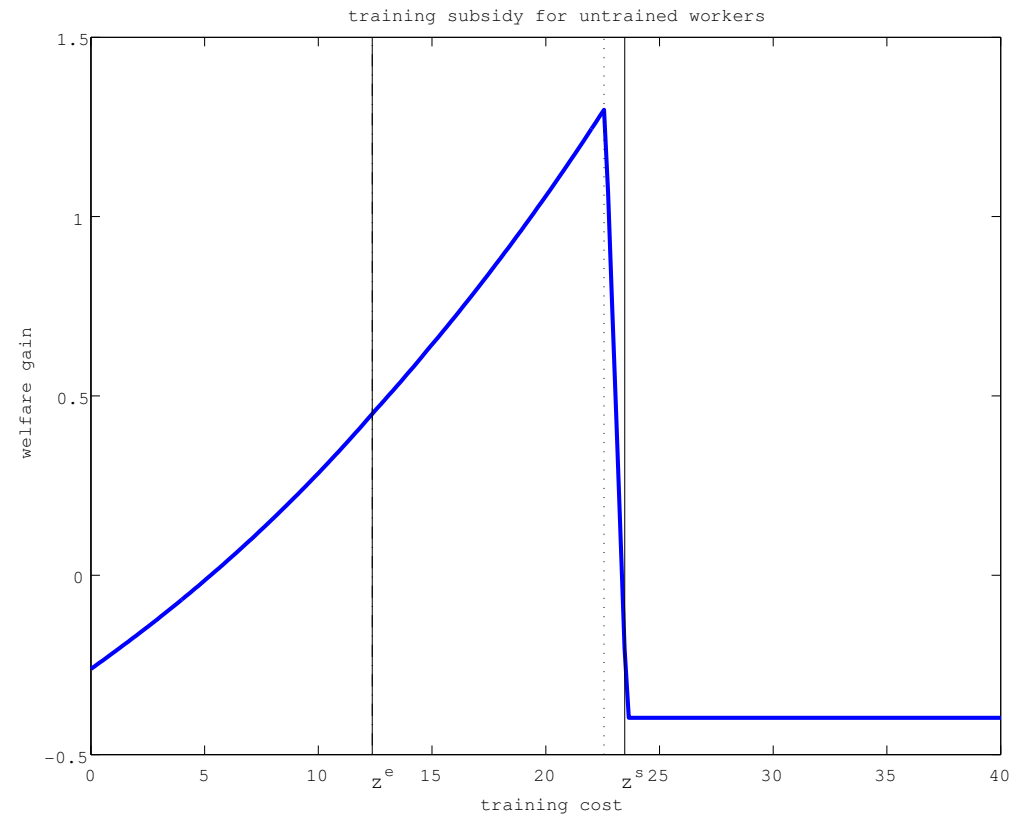

Figure 16: Net Welfare gains: Training subsidy for untrained (\%) 


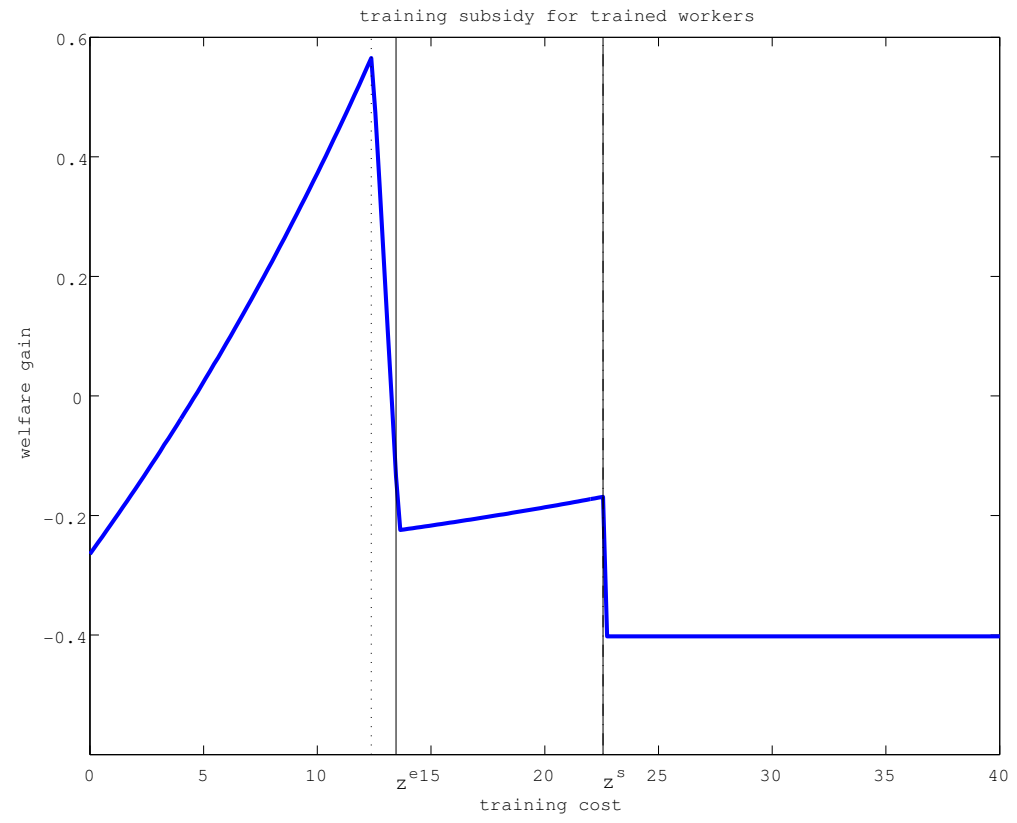

Figure 17: Net Welfare gains: Re-training subsidy for trained (\%) 